NBER WORKING PAPER SERIES

\title{
FINANCIAL CONDITIONS INDEXES: A FRESH LOOK AFTER THE FINANCIAL CRISIS
}

\author{
Jan Hatzius \\ Peter Hooper \\ Frederic S. Mishkin \\ Kermit L. Schoenholtz \\ Mark W. Watson \\ Working Paper 16150 \\ http://www.nber.org/papers/w16150
}

\section{NATIONAL BUREAU OF ECONOMIC RESEARCH \\ 1050 Massachusetts Avenue \\ Cambridge, MA 02138 \\ July 2010}

This paper will be published as part of "Proceedings of the US Monetary Policy Forum 2010" which will be available at http://research.chicagobooth.edu/igm/events/conferences/usmonetaryforum.aspx. We are grateful to our discussants (William Dudley and Narayana Kocherlakota) and to the participants in the 2010 U.S. Monetary Policy Forum for their helpful contributions. We thank Christine Dobridge, David Kelley, and Torsten Slok for help with the analysis. We also thank Lewis Alexander, Anil Kashyap, Serena Ng, Hyun Shin, and Kenneth West for valuable comments and advice, and we thank the Columbia University Macroeconomics Lunch Group and a seminar faculty group at NYU Stern School of Business for their suggestions. Finally, we thank Bloomberg, Citi, the Federal Reserve Bank of Kansas City, Simon Gilchrist, Macroeconomic Advisers, and the OECD for generously sharing their credit spread and financial conditions data. The views expressed here are those of the authors only and not necessarily of the institutions with which they are affiliated. All errors are our own. Data and replications files for the FCI and other results in this paper can be downloaded at http://www.princeton.edu/ mwatson/ The views expressed herein are those of the authors and do not necessarily reflect the views of the National Bureau of Economic Research.

NBER working papers are circulated for discussion and comment purposes. They have not been peerreviewed or been subject to the review by the NBER Board of Directors that accompanies official NBER publications.

(C) 2010 by Jan Hatzius, Peter Hooper, Frederic S. Mishkin, Kermit L. Schoenholtz, and Mark W. Watson. All rights reserved. Short sections of text, not to exceed two paragraphs, may be quoted without explicit permission provided that full credit, including (C) notice, is given to the source. 
Financial Conditions Indexes: A Fresh Look after the Financial Crisis

Jan Hatzius, Peter Hooper, Frederic S. Mishkin, Kermit L. Schoenholtz, and Mark W. Watson

NBER Working Paper No. 16150

July 2010

JEL No. E17,E44,E5

\begin{abstract}
$\underline{\text { ABSTRACT }}$
This paper explores the link between financial conditions and economic activity. We first review existing measures, including both single indicators and composite financial conditions indexes (FCIs). We then build a new FCI that features three key innovations. First, besides interest rates and asset prices, it includes a broad range of quantitative and survey-based indicators. Second, our use of unbalanced panel estimation techniques results in a longer time series (back to 1970) than available for other indexes. Third, we control for past GDP growth and inflation and thus focus on the predictive power of financial conditions for future economic activity. During most of the past two decades for which comparisons are possible, including the last five years, our FCI shows a tighter link with future economic activity than existing indexes, although some of this undoubtedly reflects the fact that we selected the variables partly based on our observation of the recent financial crisis. As of the end of 2009, our FCI showed financial conditions at somewhat worse-than-normal levels. The main reason is that various quantitative credit measures (especially issuance of asset backed securities) remained unusually weak for an economy that had resumed expanding. Thus, our analysis is consistent with an ongoing modest drag from financial conditions on economic growth in 2010.
\end{abstract}

Jan Hatzius

Goldman Sachs

200 West Street

New York, NY 10282-2198

jan.hatzius@gs.com

Peter Hooper

Deutsche Bank,NYC60-1701

60 Wall Street

New York, NY 10005

peter.hooper@db.com

Frederic S. Mishkin

Columbia University

Graduate School of Business

Uris Hall 817

3022 Broadway

New York, NY 10027

and NBER

fsm3@columbia.edu
Kermit L. Schoenholtz

NYU Stern School of Business

Department of Economics

Office 7-181

44 West Fourth Street

New York, New York 10012

kermit.schoenholtz@stern.nyu.edu

Mark W. Watson

Department of Economics

Princeton University

Princeton, NJ 08544-1013

and NBER

mwatson@princeton.edu 


\section{INTRODUCTION}

Starting in August of 2007, the U.S. economy was hit by the most serious financial disruption since the Great Depression period of the early 1930s. The subsequent financial crisis, which receded during the course of 2009, was followed by the most severe recession in the post World War II period, with unemployment rising by over five and half percentage points from its lows, and peaking at over ten percent.

This shock to the U.S. (and the world) economy has brought to the fore the importance of financial conditions to macroeconomic outcomes. In this paper we examine why financial condition indexes might prove to be a useful tool for both forecasters and policymakers, analyze how they are constructed, and provide new econometric research to see how useful a tool they can be.

\section{THE WHYS AND HOWS OF FINANCIAL CONDITIONS INDEXES}

To understand the usefulness of financial condition indexes, we will start by discussing why financial conditions matter, and then will turn to how they have been constructed in practice.

\subsection{Why Financial Conditions Matter}

Financial conditions can be defined as the current state of financial variables that influence economic behavior and (thereby) the future state of the economy. In theory, such financial variables may include anything that characterizes the supply or demand of financial instruments relevant for economic activity. This list might comprise a wide array of asset prices and quantities (both stocks and flows), as well as indicators of potential asset supply and demand. The latter may range from surveys of credit availability to the capital adequacy of financial intermediaries.

A financial conditions index (FCI) summarizes the information about the future state of the economy contained in these current financial variables. Ideally, an FCI should measure financial shocks - exogenous shifts in financial conditions that influence or otherwise predict future economic activity. True financial shocks should be distinguished from the endogenous reflection or embodiment in financial variables of past economic activity that itself predicts future activity. If the only information contained in financial variables about future economic activity were of this endogenous variety, there would be no reason to construct an FCI: Past economic activity itself would contain all the relevant predictive information. ${ }^{1}$

\footnotetext{
${ }^{1}$ For this reason, an assessment of the marginal predictive value of an FCI should purge the FCI of its endogenous predictive content. We will see later in the empirical section of this paper that existing FCIs include some mix of exogenous financial shocks and endogenous predictive components. In constructing a new FCI, we use standard
} 
Of course, a single measure of financial conditions may be insufficient to summarize all the predictive content. To simplify the exposition, we assume in this section that a single FCI is an adequate summary statistic. Later, in the empirical section of the paper, we relax and examine that assumption.

The vast literature on the monetary transmission mechanism is a natural starting place for understanding FCIs. In that literature, monetary policy influences the economy by altering the financial conditions that affect economic behavior. The structure of the financial system is a key determinant of the importance of various channels of transmission. For example, the large corporate bond market in the United States and its broadening over time suggest that market prices for credit are more powerful influences on U.S. economic activity than would be the case in Japan or Germany today, or in the United States decades ago. The state of the economy also matters: For example, financial conditions that influence investment may be less important in periods of large excess capacity.

The recent analysis of the monetary transmission mechanism by Boivin et al. (2009) classifies these channels as neoclassical and non-neoclassical. ${ }^{2}$ The first category is comprised of traditional investment-, consumption- and trade-based channels of transmission. The investment channel contains both the impact of long-term interest rates on the user cost of capital and the impact of asset prices on the demand for new physical capital (Tobin's $q$ ). The consumption channel contains both wealth and intertemporal substitution effects. Both the investment- and consumption-based channels may be affected by changes in risk perceptions and risk tolerance that alter market risk premia. Finally, the trade channel captures the impact of the real exchange rate on net exports.

The second category - or non-neoclassical set - of transmission channels includes virtually everything else. Prominent among this category are imperfections in credit supply arising from government intervention, from institutional constraints on intermediaries and from balance sheet constraints of borrowers.

These credit-related channels work in complex ways that depend on prevailing institutional and market practices. For example, factors that aggravate or mitigate information asymmetries between lenders and borrowers - such as an increase in aggregate uncertainty - can alter credit supply. In addition, the behavior of intermediaries is subject to threshold effects - like runs - that are sudden and highly nonlinear and may radically alter the link between the policy tool and economic prospects. Consequently, factors that affect the vulnerability of financial arrangements - such as changing uncertainty about the risk exposures of leveraged intermediaries - also may play an important role in assessing financial conditions.

econometric procedures to remove the endogenous component in order to isolate and study the impact of exogenous financial shocks.

${ }^{2}$ An alternative classification might distinguish between financial shocks that are directly related to monetary policy and those that are due to other factors. In this taxonomy, an FCI could be designed to measure the impact of financial variables on real activity over and above the direct effects of monetary policy via a risk-free yield curve. We employ this approach in Section 5.2 below, where we show that most of the predictive power of financial conditions for real activity reflects influences other than the evolution of monetary policy. 
Naturally, the importance of these different transmission categories may change over time. For example, a "credit view" - which emphasizes some of the non-neoclassical factors - might highlight the impact of the depletion of bank capital and the decline in borrower net worth in explaining the weak response of the U.S. economy to low policy rates in the early 1990s. A neoclassical assessment of the 1998-2002 period might highlight the role of stock prices in driving investment and, to a lesser extent, consumption.

Note that both categories of transmission channels allow for a loose link (or even for the loss of a link) between the setting of the policy tool - typically, the rate on interbank lending - and the behavior of the economy. The financial conditions that matter for future economic activity are subject to shocks from sources other than policy, in addition to policy influences. In the two examples in the previous paragraph, these shocks would include changes in the net worth of lenders and borrowers, or in the relationship between asset prices and economic fundamentals.

The impact of the policy tool on financial conditions also need not be stable (let alone linear) over time. This consideration would seem particularly important when policy tools are used beyond the usual range of variation. Indeed, at the zero interest rate bound for monetary policy, the conventional policy tool itself is no longer available.

Naturally, policymakers would like to know how less conventional policy tools affect financial conditions and the economy. Following the financial crisis of 2007-09, three unconventional policy approaches are of particular importance: (1) a commitment to keep policy rates low (hereafter, a policy duration commitment); (2) quantitative easing (QE; the supply of reserves in excess of the level needed to keep the policy rate at its target); and (3) credit easing (CE; changes in a central bank's asset mix aimed at altering the relative prices of the assets available to the private sector). ${ }^{3}$

To understand the impact of such unconventional tools, it is again necessary to focus on the specific channels by which these tools affect financial conditions. In theory, a full and complete understanding of the channels of monetary transmission could allow us to anticipate the economic impact of unconventional policy shifts. We could try to address questions such as "At the zero bound, what scale of $\mathrm{QE}$ or $\mathrm{CE}$ is expected to be equivalent in terms of future economic stimulus to a step-reduction of the conventional policy rate?" Or, "how long a policy duration commitment is needed to achieve the same effect?" Or, how much does it matter if the commitment is conditional (say, on the evolution of inflation prospects) or unconditional (that is, fixed in time)? How different is the economic stimulus if the central bank purchases $\$ 1$ trillion or $\$ 2$ trillion of mortgage-backed securities?

In practice, of course, our understanding of monetary policy transmission is far less evolved. First, in economies with sophisticated financial systems, the transmission channels are diverse

\footnotetext{
${ }^{3}$ Unlike the Bank of Japan in the late 1990s and earlier in this decade, the Federal Reserve did not target any specific level of reserves as a part of its unconventional policy apparatus. The Fed's policy focus was on credit policies that influence relative asset prices (yields), suggesting that the changing size of the balance sheet was principally a by-product of credit interventions. Nevertheless, for analytic purposes, it is useful to distinguish changes in the size of the central bank balance sheet $(\mathrm{QE})$ from changes in the mix of the central bank balance sheet (CE).
} 
and change over time. Some channels occasionally may be blocked (for example, when intermediaries are impaired or key markets fail to function), thereby altering the impact of policy changes. Second, across economies with different financial systems, the variance in the importance of specific transmission channels can be large. Third, our experience with unconventional policies is exceptionally brief and limited. At this stage, no central bank that undertook QE or CE in 2008-09 has exited from that policy stance. And, until this episode, no major central bank (aside from the Bank of Japan) had used such policies since the Great Depression.

So how does the policy transmission framework help us understand and appreciate the potential utility of an FCI? To simplify, imagine that the link between a particular FCI and the future growth rate of the economy is one-for-one. In this stylized world-depicted in the schematic in Figure 2.1 - a one-unit rise (decline) in the FCI leads to a one-percentage-point increase (decrease) in the pace of economic activity. Then, since policy is transmitted to the economy solely via financial conditions, the FCI would indicate whether a change in policy will alter economic prospects. It would summarize all the information about financial conditions - arising from both policy and from non-policy influences - that is relevant for the economic outlook. If policymakers changed their policy tool - conventional or unconventional - with a goal of altering economic behavior, the FCI would inform them if they will succeed.

Of course, nothing about monetary policy or its assessment is so simple. First, the link between financial conditions and economic activity evolves over time. Changing mechanisms of finance mean that the indicators needed to capture the financial state also change. As an example, consider how the rising share of ARMs over recent decades alters the impact of short-term interest rates on the cost of home mortgages and on housing activity. Or, consider how the expansion of highly leveraged shadow banks in the decades after 1980 altered the link between the level of interest rates and the supply of credit.

Second, the importance of factors other than monetary policy on financial conditions varies over time. Bouts of euphoria and pessimism can prompt asset bubbles and crashes even in periods where monetary policy tools are set close to long-run norms. Long periods of stability can erode risk awareness (consider the impact of steadily rising house prices over the period from the Second World War to 2006). And, pro-cyclical aspects of regulation, accounting and institutional risk management can amplify the cyclicality of credit supply and the swings in market risk premia that affect economic prospects. In recent years, the impact of such non-monetary influences on financial conditions seems unusually high.

Third, the response of financial conditions to policy changes - even aside from non-policy shocks - may change. Imagine, for example, that a central bank chooses to lower interest rates in response to an oil price shock. How will long-term interest rates and equity prices change? Presumably, a central bank that gains anti-inflation credibility over time will experience a changing response to its policy actions.

Fourth, forces other than financial conditions also affect the performance of the real economy. Examples include productivity shocks, commodity prices, and the "animal spirits" of consumers 
and business managers. While there is a financial aspect to most of these forces, the assumption that their only impact on the real economy occurs via financial conditions is clearly too strong.

In light of these considerations, policymakers cannot know the extent to which a policy change will alter an FCI, or the extent to which a change in an FCI foreshadows a change in the economy. Even so, an effective FCI may provide policymakers with a useful guide, especially in periods when the link between policy setting and financial conditions seems weak, or when the policy tools in use are stretched beyond their normal range. Just as a Taylor-type rule can inform (and helpfully constrain) the use of policy discretion, an FCI can serve as one guide to the effective stance of policy, after taking into account all the other factors that affect financial variables.

Consider, for example, the period of Federal Reserve rate hikes from 2004 to 2006. In this era of the "Greenspan conundrum," a number of FCIs in wide use suggested that broad financial conditions remained accommodative despite rising policy interest rates and a flattening yield curve. The same FCIs also showed the most extremely restrictive conditions in late 2008, even after the funds rate hit zero, the authorities had introduced a policy duration commitment, the Fed balance sheet had doubled in size, excess reserves had ballooned by a factor of 50, and policymakers had undertaken or announced plans for massive purchases of securities with some degree of credit risk. Indeed, a comparison of the paths for a specific FCI that we will construct later over previous periods of policy tightening or periods of policy easing shows that the 200406 and 2007-09 episodes are outliers in opposite directions. Precisely for that reason, they provide useful information to policymakers.

To be sure, FCIs are not underpinned by a structural model derived from stable underlying microeconomic foundations. As such, their stability and predictive power is questionable. They are certainly vulnerable to the Lucas critique: Policy changes (or, more precisely, policy regime changes) reduce their utility. However, structural models with a role for a credit sector and for unconventional monetary policy are only now beginning to be explored, and they remain rudimentary (see Gertler and Kiyotaki, 2009 and Brunnermeier and Sannikov, 2009). It may be many years before such structural models can provide a reasonable basis for assessing specific policy choices. From a practical point of view, then, the use of reduced-form statistical techniques like those employed in creating FCIs is virtually the only means currently available to assess the impact of specific unconventional policy choices at the zero bound.

\subsection{Which Variables to Include in an FCI}

In principle, the range of potential financial measures to include in an FCI is quite vast. Consider, for example, the neoclassical channels of transmission. There is a long list of financial price measures that influence the user cost of capital, including the interest rates that firms pay to borrow (both short- and long-term) and the price at which they could raise new equity capital. Not surprisingly, equity prices, the shape of the yield curve and measures of credit risk have long been used as financial indicators of future economic activity, and are common components of FCIs. Similarly, prices that affect household wealth - including those of equities and houses - or consumer interest rates that affect the tradeoff between consumption today and consumption tomorrow would be natural candidates for an FCI. 
The non-neoclassical or credit channels point to an even broader array of possible FCI components, including measures of liquidity, of borrower risk, and of the capacity and willingness of intermediaries to lend. In light of information asymmetries, the value of collateral often is critical in determining whether borrowers can obtain credit, so the asset prices of key types of collateral may be useful in an FCI. Uncertainty about the value of collateral also can be an obstacle to obtaining credit, so the volatility of these asset prices may be relevant, too. Finally, liquidity conditions (including the ability to roll over debt and to sell assets easily) and the status of their own capital also influence the propensity of intermediaries to lend. For some intermediary-related indicators - like the excess cost of an interbank loan above the expected policy rate - it is difficult to disentangle the liquidity component from the borrower-risk component, but both matter for the credit channels of transmission.

In contrast to the neoclassical channels, which are generally measured via asset prices or interest rates, some of the non-neoclassical channels may be measured via quantity indicators or even surveys. The volume of transactions helps to quantify actual access to credit. In addition, survey measures of lending standards and conditions may be useful in assessing prospective access to credit.

\subsection{How FCIs Have Been Constructed in Practice}

Early research on financial conditions centered on the slope of the yield curve. Studies published in the late 1980s and early 1990s found the yield curve to be a reliable predictor of economic activity (Estrella and Hardouvelis, 1991; Harvey 1988; Laurent 1989; Stock and Watson, 1989). The spread between the fed funds rate and 10-year Treasury yield has been a key component of the Conference Board's index of leading indicators since 1996. Credit risk, as measured by the commercial paper-Treasury bill spread, has also been used as a leading indicator of output since the late 1980s (Friedman and Kuttner 1992; Stock and Watson, 1989), and Gilchrist, Yankov, and Zakrajšek (2009) have recently proposed improved credit risk spreads with good forecasting performance over the past decade. The yield curve has been found to outperform other financial variables in terms of predicting recessions, though stock market performance has been found by some to be a useful recession predictor as well (Estrella and Mishkin, 1996). Stock market variables have been included in indexes of leading indicators since the 1950s (Zarnowitz, 1992).

The Bank of Canada (BOC) pioneered work on broader financial condition measures in the mid1990s, when it introduced its monetary conditions index (MCI, Freedman, 1994). For the BOC, the exchange rate was the most important additional variable. Its MCI, therefore, consisted of a weighted average of its refinancing rate and the exchange rate. The weights were determined via simulations with macroeconomic models designed to quantify the relative effect of a given percentage change in each variable on GDP or final demand. In the case of Canada, a relatively open economy, the exchange rate was given a weight equal to about one-third that of the refinancing rate. For a more closed economy like the United States, the weight given to the exchange rate is considerably smaller. The MCI was used to help evaluate how much adjustment in the refinancing rate might be needed to offset the macroeconomic effects of a swing in the 
exchange rate in order to maintain a desired stance of monetary conditions or degree of monetary accommodation.

Over the course of the late 1990s, MCIs along the lines constructed by BOC became a widely used tool to assess the stance of monetary policy in many countries. Moreover, the scope of variables augmenting the effects of policy rates was broadened to include long-term interest rates, equity prices, and even house prices (on the grounds that rising house prices increased the borrowing capacity of households). These broader measures became known as financial condition indexes (FCIs) in order to distinguish them from MCIs.

A variety of methodologies for constructing FCIs have been developed over time, and tend to fall into two broad categories: a weighted-sum approach and a principal-components approach. In the weighted-sum approach, the weights on each financial variable are generally assigned based on estimates of the relative impacts of changes in the variables on real GDP. These estimates or weights have been generated in a variety of ways, including simulations with large-scale macroeconomic models, vector autoregression (VAR) models, or reduced-form demand equations.

The second broad approach is a principal components methodology, which extracts a common factor from a group of several financial variables. This common factor captures the greatest common variation in the variables and is either used as the FCI or is added to the central bank policy rate to make up the FCI (this latter method is a combination of the weighted-sum approach and the principal-components approach).

In most cases, financial condition indexes are based on the current value of financial variables, but some take into account lagged financial variables as well. Some FCIs can be interpreted as the summarizing the impact of financial conditions on growth, others can be interpreted as measuring whether financial conditions have tightened or loosened.

Though the specific variables included in various FCIs differ considerably, there are commonalities. Most FCIs include some measure of short-term interest rates, long-term interest rates, risk premia, equity market performance, and exchange rates. In the weighted-average approach, some FCIs use the outright levels of each variable, and some standardize the variables by subtracting the variable's mean and dividing by its standard deviation in each case. The components are predominantly rates or financial prices (or derivatives of prices). In a few cases a stock market wealth or market capitalization variable is included. One FCI uses a Federal Reserve survey of lending standards; another FCI incorporates energy prices and a measure of narrow money. None of the FCIs include stock or flow measures of any broader categories of credit.

In what follows, we consider seven well-established FCIs: the Bloomberg FCI, the Citi FCI, the Deutsche Bank (DB) FCI, the Goldman Sachs (GS) FCI, the Kansas City Federal Reserve Financial Stress Index (KCFSI), the Macroeconomic Advisers Monetary and Financial Conditions Index, and the OECD FCI. While a number of other FCIs have been developed, these particular indexes span a wide range of construction methodologies and financial variables, 
and most are generally available. ${ }^{4}$ Figure 2.2 plots the various FCIs. Table 2.1 includes a comprehensive list of the variables included in each index considered and Table 2.2 provides a summary of each index's methodology. A short description of each index follows.

\section{Bloomberg Financial Conditions Index}

The Bloomberg FCI is readily accessible to those in financial markets and updated daily, making it a convenient measure to track financial conditions. The index is an equally weighted sum of three major sub-indexes: money market indicators (one-third weight), bond market indicators (one-third weight), and equity market indicators (one-third weight) (Rosenberg, 2009). Each major sub-index is then made up of a series of underlying indicators, which receive an equal weight in that sub- index. Each indicator is standardized to show the number of standard deviations above or below the index's 1991 to mid-2007 average (the Z-score). The overall FCI is also standardized in that manner. The index consists of 10 variables in total, with history available from 1991.

\section{Citi Financial Conditions Index}

The Citi FCI is a weighted sum of six financial variables, where the weights were determined according to reduced-form forecasting equations of the Conference Board's index of coincident indicators (the six-month percent change in the coincident index) (D'Antonio, 2008). The variables in the index include corporate spreads, money supply, equity values, mortgage rates, the trade-weighted dollar, and energy prices; all nominal values are deflated. The FCI uses various transformations and lags of the indicators, according to what anticipates movements in the coincident index at a horizon of roughly six months. This index is available from 1983.

\section{Deutsche Bank Financial Conditions Index}

Deutsche Bank utilizes a principal components approach in its FCI (Hooper, Mayer and Slok, 2007; Hooper, Slok and Dobridge, 2010). The first principal component is extracted from a set of seven standardized financial variables that include the exchange rate, and bond, stock, and housing market indicators. The FCI is then set to the weighted sum of this principal component and the target federal funds rate, where the weights are determined in a regression of real GDP growth on the financial variables and lagged GDP growth. The level of the index can be interpreted as the percentage point drag or boost to GDP from financial conditions at a point in time, depending on whether the index is negative or positive, respectively. The Deutsche Bank index is available from 1983.

\section{Goldman Sachs Financial Conditions Index}

The Goldman Sachs FCI is a weighted sum of a short-term bond yield, a long-term corporate yield, the exchange rate, and a stock market variable (Dudley and Hatzius, 2000; Dudley, Hatzius and McKelvey, 2005). The Federal Reserve Board's macroeconomic model (the FRB/US model), together with Goldman Sachs modeling, were used to determine the weights. Since 2005, the long-term corporate yield has been measured as a sum of the 10-year swap rate and the 10-year credit default swap spread (CDX); prior to 2005, the less-liquid Moody's Arated corporate bond index was used. As the CDX only started trading in 2003, a longer-dated

\footnotetext{
${ }^{4}$ Other U.S. financial conditions indexes include those developed by Beaton, Lalonde and Luu (2009); Goodhart and Hoffmann (2001); Montagnoli and Napolitano (2006); and Swiston (2008).
} 
FCI — from 1980 — was created by splicing the old and new indexes. An increase in the Goldman Sachs FCI indicates tightening of financial conditions, and a decrease indicates easing. The index is set so that October 20,2003 $=100$. Unlike the other indexes, the Goldman Sachs index exhibits a noticeable downward trend because it uses levels of the financial variables, as opposed to using spreads or using changes in the variables as in most other indexes.

\section{Federal Reserve Bank of Kansas City Financial Stress Index}

This index was developed in early 2009, and is a principal-components measure of 11 standardized financial indicators (Hakkio and Keeton, 2009). The financial variables chosen by the Federal Reserve Bank of Kansas City can be divided into two categories: yield spreads and asset price behavior. They were chosen to satisfy three criteria: 1) be available monthly with a history extending back to at least 1990; 2) be market prices or yields; and 3) represent at least one of five financial stress features that were identified by the Kansas City Federal Reserve (including increased uncertainty about assets' fundamental values, or decreased willingness to hold risky assets). A positive index value indicates that financial stress is higher than its longer term average, and vice versa for a negative value. The series is updated monthly and history is available from 1990.

\section{Macroeconomic Advisers Monetary and Financial Conditions Index}

Macroeconomic Advisers constructed its monetary and financial conditions index in the late 1990s to take into account the dynamic effects of financial variables on GDP over time (Macroeconomic Advisers, 1998). They developed a "surface impulse response" methodology in aggregating the five different financial variables into an FCI: a real short rate, real long rate, dividend ratio, real exchange rate, and real stock market capitalization. Response functions were generated by estimating the partial effects of changes in the financial variable on real GDP growth over time using simulations with MA's large-scale macroeconomic model. The response functions were then inverted and aggregated so that the MA FCI at any point in time shows the combined effects of current and past changes in each of the financial variables on real GDP growth in the current period. The index incorporates 38 quarters of financial variable lags and is available from 1982:Q4.

\section{OECD Financial Conditions Index}

The OECD FCI was constructed in 2008 and is a weighted sum of six financial variables (Guichard and Turner, 2008), where the variables are weighted according to their effects on GDP over the next four to six quarters. One major difference between this index and others is that it includes a variable for tightening of credit standards: the Federal Reserve Senior Loan Officer Survey's series for the net percent of banks tightening standards for large and medium-sized firms. The OECD set the index weights from a regression of the output gap on a distributed lag of the financial indicators. The weights were normalized relative to the change in interest rates, so that a one unit increase in the FCI is equivalent to the GDP effects of a one-percentage-point increase in the real long-term interest rate. A one-unit increase in the FCI indicates that tighter financial conditions could reduce real GDP by about 0.6 percentage points over the next 4 to 6 quarters. The OECD FCI has history back to 1995. 
When we compare movements in these different indexes in Figure 2.2, we see the following:

- Despite wide ranges of coverage and methodologies, all the indexes show a large deterioration of financial conditions during the past two years and a strong bounce back (to about neutral) by the latter part of 2009.

- There is some noticeable disagreement about how stimulative financial conditions were during the years leading up to the current crisis, and about whether or not the deterioration in the recent crisis was unprecedented relative to experience over the past two decades.

- Some of this disagreement may hinge on the relative weight placed on monetary policy, which tends to run counter to and mitigate the effects of swings in private market financial conditions. Indexes that showed the deterioration of financial conditions during the recent crisis to be unprecedented did not include the level of fed funds or closely related short term rate. Indexes that include the level of the policy rate or a close substitute showed the recent decline to be closer in magnitude to the decline that occurred around the beginning of the decade.

\section{TESTING THE PREDICTIVE POWER OF FINANCIAL CONDITIONS}

In this section we turn to an empirical investigation of how well financial conditions anticipate movements in real economic activity. We begin by assessing the predictive performance of single financial variables that have been viewed as useful leading indicators - the term spread, stock returns, and so on. We then turn to the performance of the broader measures of financial conditions as captured by the FCIs discussed in Section 2.

\subsection{Prediction Tests with Single-Variable Financial Indicators.}

To establish a baseline for judging performance, we begin by assessing the predictive performance of five individual financial variables that are commonly considered to be useful leading indicators:

1. The term spread (the spread between 10-year Treasury notes and the federal funds rate).

2. Real M2 (nominal M2 deflated by the personal consumption expenditures deflator).

3. The S\&P 500 stock price index.

4. The level of the federal funds rate as a key indicator of monetary policy.

5. The short-term credit spread (the spread between the three-month commercial paper rate and the three-month Treasury bill rate).

The first three of these are well established as the financial components of the Conference Board's index of leading indicators. The other two are commonly used as well. ${ }^{5}$

\footnotetext{
${ }^{5}$ The literature on the forecasting performance of these and other financial indicators is vast. Stock and Watson (2003) surveys the pre-2003 literature.
} 
To gauge the performance of these five indicators, we considered their ability to predict (over horizons of two and four quarters ahead) the growth of four different measures of real economic activity: real GDP, payroll employment, the index of industrial production (IP), and the civilian unemployment rate. Our interest was in determining how well the financial variables would perform after taking into account each activity variable's autoregressive structure (the ability of the variable's recent historical movements to predict its future movements). The analysis was done both in-sample and post-sample. Our approach is in the spirit of Bernanke (1990), who tested the marginal forecasting power of various interest rate spreads for economic activity and inflation after taking into account the autoregressive structure of each variable.

The in-sample regression specification we employed was:

$$
y_{t+h}-y_{t}=\beta_{0}+\sum_{i=1}^{p_{x}} \phi_{i} \Delta y_{t+1-i}+\sum_{i=1}^{p_{x}} \gamma_{i} x_{t+1-i}+e_{t+i}
$$

where $y_{t}$ denotes the real activity indicator (the logarithms of real GDP, employment, or IP or the level of unemployment rate), and $x_{t}$ denotes the financial indicator (the first difference of the federal funds rate, the first difference of the logarithm of real M2, the first difference of the logarithm of the SP500, or the level of the interest rate spreads). Our data are quarterly, and $h$ denotes the forecast horizon (so that $h=2$ or 4 quarters). The parameters $p_{y}$ and $p_{x}$ denote the number of lags of $\Delta y$ and $x$ used in the regressions, which were fixed at $p_{y}=p_{x}=4$ for the insample analysis.

\section{In-sample results.}

Table 3.1 shows results for these in-sample regressions estimated using data for most of the past five decades, but not including the current recession $(t=1961$ :Q1 -2006 :Q4). (Forecasts for the current recession are examined in the post-sample results below.) The table is divided into two panels, the top panel showing the results for growth over the next two quarters and the bottom panel showing the results for growth over the next four quarters. In each panel, the activity variable $y$ being predicted is shown in the top row and the financial indicator $x$ being used to predict it is listed in the left column. Three statistics are given for each regression:

- $\quad R_{x / \Delta y}^{2}$ is the partial $R^{2}$ for the lags of $x$ given the lags of $\Delta y$, which shows the proportion of the overall variance in the activity variable that is explained by the financial variables net of the variance explained by the autoregressive component of the regression.

- $F$ is the $F$-statistic testing the hypothesis that the coefficients on the lags of $x$ are zero with its $p$-value shown in parentheses. (A $p$-value less than 0.05 means that the estimated coefficients on lags of $x$ are statistically significantly different from zero at the 5\% significance level.) 
- $Q L R$ is the Quandt likelihood ratio $F$-statistic which tests the null hypothesis that the coefficients on lags of $x$ are stable over the sample period. Again, $p$-values are shown in parentheses, and a $p$-value that is less than 0.05 (corresponding to QLR statistics greater than 4.1) indicates statistically significant evidence of instability in the coefficients. ${ }^{6}$

The results indicate that the financial variables are useful in explaining the variance in the two and four-quarter ahead growth of the activity variables. The partial $R^{2}$ s generally fall in range of 0.1 to 0.2 , and the $F$-statistics are uniformly significant at the $5 \%$ level. However, the $Q L R$ statistics show substantial evidence of instability (31 of the 40 QLR statistics are significant at the $5 \%$ level). While the specific source of instability is unclear, the outcome should not be surprising. The potential for instability was highlighted in Section 2 that focused on the conceptual background of financial conditions indicators. Just to recall, such in-sample instability can arise for a wide variety of reasons, including financial innovation, structural changes in the economy, and threshold effects (and other nonlinearities that are not captured in the linear model). Inclusion of the lagged activity indicators may not eliminate these sources of instability. The statistical fit was generally at least as good for 4-quarter-ahead results as for 2quarter-ahead predictions, and there was no evidence of a greater incidence of instability at the longer horizon. Among the five separate financial factors, the stock market index exhibited greater stability, especially at the 4-quarter horizon, but it also explained a somewhat smaller portion of the total variance than the others.

\section{Post-sample tests}

Our post-sample prediction analysis is carried out using "pseudo-out-of-sample" calculations that rely on the same regression specification used above, but estimated recursively through the forecast period. ${ }^{7}$ Specifically, forecasts at time period $t$ are constructed by estimating the regression coefficients using data from the beginning of the sample through period $t$; these estimated regression coefficients are then used to forecast $y_{t+h}$. The process is repeated to construct forecasts at time $t+1$, and so on through the end of the sample (2009:Q4). The lag lengths on the $x$ 's and $\Delta y$ 's were chosen (at each forecast date) by BIC, a standard method for estimating lag-lengths. ${ }^{8}$ The pseudo-of-sample predictions were started in 1971 to allow for a

\footnotetext{
${ }^{6}$ The QLR (Quandt Likelihood Ratio) test statistic is a version of the familiar Chow-test for structural instability, which is used when there is uncertainty about the potential break-date in the coefficients. The QLR test statistic is the largest of the Chow $F$-statistics computed for every possible break-date in the middle $70 \%$ of the sample period. For a textbook discussion of the test see Stock and Watson (2007, Chapter 14).

7 These are called "pseudo-" out-of-sample, because they were not actually computed in real-time over the sample period. Importantly, in our context, they do not reflect revisions in the real activity indicators or real M2.

${ }^{8}$ BIC (Bayes information criteria), also called the SIC (Schwartz information criteria), balances the tradeoff between improved model fit (reducing a regression's sum of squared residuals) and increases in sampling error (larger coefficient standard errors) associated with augmenting the forecasting model with additional lags. See Stock and
} 
minimum of 40 quarterly observations in the regressions used for the initial forecast. As a benchmark for comparison, we also constructed pseudo-out-of-sample forecasts using an autoregressive model (which had the same form of the model above, but excluded the financial variable $(x)$ regressors $)$.

Table 3.2 shows the root mean square forecast errors (RMSE) computed for the post-sample predictions produced by the various equations. The quarterly results are aggregated (averaged) into the eight 5-year subperiods since 1970 shown in the top row of the table. As with the insample results in Table 3.1, this table too is split in half, with the top half devoted to 2-quarter ahead predictions and the bottom half 4-quarter-ahead predictions. In each half, the top panel of data shows the RMSE for the autoregressive (AR) models (excluding financial factors) for each of the four real activity variables. The rows below show results for the equations with each of the five financial factors (listed in the first column). In the top half of the table (for $h=2$ ) we show somewhat more detailed results for the fed funds model to help explain the results below. Each of the rows for fed funds shows the root mean square forecast error relative to the associated RMSE for the AR model. For example, in the first subperiod, 1970:Q1-1974:Q4, the RMSE for predicting real GDP was 1.03 (that is, the RMSE using fed funds was 1.03 times greater than the corresponding RMSE for the autoregressive model). Similarly, the relative RMSEs for employment, IP, and unemployment were 1.08, 1.24 and 1.09, respectively. The average of these four relative RMSEs, 1.11, is reported in the next line down. And in the lines that follow, similarly constructed averages are reported for the other four financial indicators. The more detailed results underlying these averages for the other indicators are presented in the appendix tables.

Several notable patterns emerge in the results:

- First, in the benchmark autoregressive models, prediction errors dropped substantially after mid-1985 and remained low for the next 20 years. We view this pattern as evidence of the Great Moderation. The recent reemergence of pronounced volatility of economic activity is evident in the substantial rise of the RMSE of the AR models in the latest subperiod.

- Second, at both two and four-quarter forecast horizons, the models including financial indicators generally improved on AR forecasts (relative RMSEs < 1) through the mid1980s, after which their performance was relatively worse. The five simple financial indicators generally did not enhance - indeed they tended to worsen - the accuracy of post-sample prediction of economic activity during the Great Moderation. During the most recent period, with increased economic volatility, the simple financial indicator models, on average, were about on a par with the AR models.

Watson (2007, Chapter 14). In this application we allow $p_{y}$ to take on values between 0 and 4 , and $p_{x}$ to take on values between 1 and 4 (so that at least one lag of $x$ enters the regression). 
- Third, the financial indicator models performed especially poorly relative to the AR models in the second half of 1980s. The result should not come as a surprise in light of the in-sample results pointing to instability. ${ }^{9}$ While the specific reasons for this breakdown are not immediately evident, the discussion in Section 2.1 highlighted several potential explanations.

- Fourth, among the five simple indicator models, the stock market variable outperformed the AR model over the past decade, perhaps reflecting the relative importance of wealth effects on private spending during the 2001 and 2007-09 recessions. The credit spread also did relatively well during the most recent five years. ${ }^{10}$ These findings are consistent with our earlier observation that the credit spread and especially the stock market variable showed greater evidence of in-sample stability.

These results - including the evidence of in-sample instability and, with some exceptions, the failure to outperform simple autoregressive relationships in post-sample predictions in recent decades - are consistent with results found by earlier researchers (Stock and Watson (2003)).

We see two ways to account for the evidence of instability in using simple financial indicators to predict real economic activity. Either "financial conditions" are unstable predictors of activity, or the simple indicators we have considered are unstable indicators of financial conditions more broadly. The tests we consider next should shed some light on this issue.

\subsection{Prediction Tests with Financial Conditions Indexes.}

As we discussed in Section 2, FCIs pool information across multiple financial indicators, and therefore tend to be more representative of broad financial conditions than any single indicator could be. To see if this pooling of information improves performance in predicting real activity, we have used the same pseudo-out-sample analysis outlined above for the various FCIs described in Section 2.

Before showing the results, we highlight two features of the FCIs previously discussed in Section 2 that make this exercise different from the exercise using the individual financial indicators.

\footnotetext{
${ }^{9}$ The pattern of instability also surfaces when carrying out the analysis using regressions estimated over 40 -quarter rolling samples (that is, 40-quarter fixed sample period lengths) rather than recursive estimates (that is, using fixed starting points with sample periods that lengthen with each new observation). Overall, these rolling regressions did not perform better than the recursive results, but they marginally outperformed the recursive regressions during the latter 1980s.

${ }^{10}$ We also carried out the analysis using the credit spreads constructed in Gilchrist, Yankov, and Zakrajšek (2009; hereafter GYZ) that are available for the post-1990 period. GYZ construct 20 spreads that differ in maturity and default risk. Over the final two five-year periods (2000:Q1-2004:Q4, and 2005:Q1-EOS), the average RMSEs were 0.98 and 0.78 for $h=2$ and 1.22 and 0.87 for $h=4$. Results using a single principal component from the 20 spreads were similar ( 0.96 and 0.71 for $h=2$ and 1.13 and 0.83 for $h=4)$. Thus, consistent with results reported in GYZ, we find that their default spreads forecast relatively well during the 2000 's.
} 
First, a long history is available for the individual indicators, but the available history for the FCIs is much shorter. The various FCIs are available over different sample periods; the Goldman-Sachs (GS) index starts in 1980:I and has the longest history, while the OECD index starts in 1995:I and has the shortest history. The second feature is that several of the FCIs were constructed by fitting real activity measures over some portion of the period that we used for our post-sample tests. This may impart an upward bias to their measured forecasting accuracy in our tests of their performance in predicting real activity. ${ }^{11}$

Pseudo-out-of-sample forecasts were computed as in the previous section, but with the various FCIs used as the $x$ variables in the regressions. The results for this forecasting exercise are summarized in Table 3.3, which shows the average relative RMSEs for each FCI over the same 5-year periods used in Table 3.2. The limited history of the FCIs leads to a large number of blank entries in the table because forecasts are constructed from regressions using a minimum of 40 quarterly observations. Thus, for example, because the GS FCI begins in 1980:Q1, the first 2quarter ahead forecast was constructed in 1991:Q4 to allow for a maximum of 4 lags.

The key findings in Table 3.3 can be summarized as follows:

- Pooling of information appears to improve the predictive ability of financial indicators, at least during periods of unusual financial stress. The FCIs outperformed the single financial indicator models on average, and the best of the FCIs outperformed the stock market index (the best of the single indicator models). However, the average performance of the FCIs was not better than that of the stock market index.

- During the 1990s, some of the available FCIs did not do as well as the AR model (relative RMSEs > 1.0) or the single indicator models. After 2000, the FCIs showed a noticeable improvement relative to both the AR model and the single financial indicator models.

- There is some evidence that in-sample overfitting is not a significant factor: During the most recent five-year period, the DB (PC) and the DB (FCI) performed comparably despite the former's advantage of being constructed explicitly to predict GDP.

- Over the past decade, the KCFSI performed near the average of the FCIs, so we use it below as representative.

\footnotetext{
${ }^{11}$ For this reason we also used the principal component (PC) portion of the DB index, which is not subject to such a bias and should therefore give us some indication on the potential significance of this bias. Because the GS index exhibits substantial low-frequency ("trending") behavior, we carried out the analysis using two versions of the index, level and first-difference. Figure 2.2 shows the year-over year difference in the GS index.
} 


\section{CONSTRUCTION OF A NEW FINANCIAL CONDITIONS INDEX}

We seek to address three limitations of earlier financial conditions indexes. First, previous FCIs cover only a limited span of history. Second, the narrowness of the underlying series included in the indexes results in the exclusion of potentially important financial conditions. Third, previous FCIs do not purge their measures of endogenous movements related to business cycle fluctuations or of monetary policy influences and so are less representative of the shocks to the financial system.

In this section we develop a new, broader index of financial conditions in an effort to overcome the limitations of previous indexes. An important goal was to see if we could improve predictive performance compared to existing FCIs, especially in light of the perceived importance of shifts in financial conditions in driving the most recent recession and recovery. Accordingly, we established two criteria for the design and construction of a new index. First, it needed to cover a wide range of financial variables, substantially wider than the coverage of any of the existing FCIs covered. Second, it needed to have a relatively long history, ideally going back at least to the early 1970s. As we will see, there is a tension between wide coverage and long history (many interesting financial variables have become available only relatively recently), but we were able to overcome some of this tension by using econometric methods designed for unbalanced panel datasets. Third, we purged the underlying series that make up the financial conditions index of cyclical influences.

\subsection{Selection of Financial Variables}

The 45 variables we selected to include in our index are listed in Table 4.1. Our starting point for the selection of these variables was the coverage of existing FCIs - we wanted to begin with a relatively full representation of the variables included in the FCIs surveyed in Section 2 (as laid out in Table 2.1). This did not mean complete coverage of all the variables in Table 2.1, as there is a fair amount of overlap of very similar but not identical variables used in the different FCIs; for example, while Table 2.1 lists several broad measures of the stock market, we felt that only one was needed. We chose not to include the fed funds rate or a close substitute (such as the short-term Treasury rate). At a later stage in this analysis, we also purge the FCI of monetary policy influences that may arise from including the yield curve in the FCI. 
Next, we wished to fill in areas that were not fully covered by existing FCIs. Most FCIs are dominated by interest rate level or spread variables and by asset price variables, which we have captured as indicated in rows 1-20 of Table 4.1. We have added several price and spread variables that were not included in other FCIs, including new-car loan rates, jumbo mortgage rates, and home prices. (These variables are denoted by the " $\mathrm{X}$ " in the third column of Figure 4.1.)

Existing FCIs also include few quantity or flow variables, and only one FCI included a survey variable. During the recent financial meltdown, these indicators appeared to become much more important than they had been in the past. At the same time, price signals became potentially less reliable as markets seized up, nonprice credit conditions tightened dramatically, and credit flows slowed abruptly. In an effort to capture these effects, we added 15 financial stock and flow variables to the list, including a representative sample of bank and non-bank credit variables in a variety of markets. We also included seven survey indicators of financial conditions from the Fed's Senior Loan Officer Survey of bank lending conditions, the University of Michigan's survey covering consumer credit conditions, and the National Federation of Independent Business survey of small business credit conditions. ${ }^{12}$

\subsection{Historical Coverage}

Not all of the financial indicators we selected have histories going back as far as desired. This unbalanced nature of our data panel is exhibited in Figure 4.1. For clarity, the start date of each of our financial indicators is given in the fifth column of Table 4.1. Only one-fourth of the 45 series go back to the beginning of the 1970s, but two-thirds go back to the early 1980s, and about $90 \%$ to the mid-1990s. Fortunately, nearly half of the variables in the new areas we have chosen to stress - stocks outstanding, flows, and surveys - go back to the 1970s. Many of the more recent series have become available as new markets emerged over time, including, for example, those relating to securitized consumer and business credit and credit default swaps.

\subsection{Econometric Approach}

\footnotetext{
12 A natural question is whether the richness of our FCI also allows us to capture the vulnerabilities associated with high levels of financial leverage, which have become so obvious during the financial crisis. The answer is "not really." We do include broker-dealer leverage, measured as the ratio of total assets to total equity capital of brokerdealers, as well as several indicators that proxy for leverage in the broader economy, such as the market capitalization of financial stocks and the economywide level of debt. However, our empirical approach is only able to identify the predictive power of a decline in leverage for subsequent economic weakness, not that of a high level of leverage. The reason is that most if not all leverage measures are statistically non-stationary, so we need to transform them into growth rates before including them in our analysis. At least in theory, a different statistical approach that aims to capture "cointegrating" relationships between the levels of different variables may be capable of capturing such information. However, such an approach would probably need to impose considerably more theoretical structure on the relationship between financial measures and economic outcomes than we do in our more flexible econometric approach.
} 
Like some of the FCIs discussed above, we summarize the information in the indicators using principal components. However, our methods differ from standard applications in three key ways. First, we allow for unbalanced panels (that is, for data series that begin and end at different points in the sample). Second, we eliminate variability in the financial variables that can be explained by current and past real activity and inflation so that the principal components reflect exogenous information associated with the financial sector rather than feedback from macroeconomic conditions. ${ }^{13}$ Third, we summarize the financial variables using more than a single principal component. This subsection summarizes the methods used to compute the principal components of the 45 financial series. The forecasting performance of these principal components is discussed in the next subsection.

Let $X_{i t}$ denote the $i$ 'th financial indicator at time $t, Y_{t}$ denote a vector of macroeconomic indicators (the growth rate of real GDP and inflation in our implementation) and consider the regression equation

$$
X_{i t}=A_{i}(\mathrm{~L}) Y_{t}+v_{i t}
$$

where $v_{i t}$ is uncorrelated with current and lagged values of $Y_{t}$, and thus represents the financial variable purged of its relation with current and lagged $Y$. Suppose that $v_{i t}$ can be decomposed as

$$
v_{i t}=\lambda_{i}^{\prime} F_{t}+u_{i t}
$$

where $F_{t}$ is a $k \times 1$ vector of unobserved financial factors, and $u_{i t}$ captures "unique" variation in $v_{i t}$ that is unrelated to $F_{t}$ and $Y_{t}$. Under the assumption that the $u_{i t}$ are uncorrelated (or "weakly" correlated) across the financial variables, the vector $F_{t}$ captures the covariation or comovement in the financial indicators. Thus, the goal of the econometric analysis is to estimate $F_{t}$.

There is a large literature on estimating common factors in models such as this. Much of the modern literature (see surveys in Bai and Ng (2008) and Stock and Watson (2006, 2010)) studies so called "approximate dynamic factor models" in which $F_{t}$ and $u_{i t}$ are serially correlated, and data are available on a reasonably large number of indicators $(i=1, \ldots, n$ where $n$ is large) over a reasonably large sample period ( $t=1, \ldots, T$ where $T$ is large). A key result in this literature is that least squares estimators of $F$ (principal components) are sufficiently accurate that they can be used in subsequent regression analysis (including predictive regressions like ours) with no first-order loss in efficiency or modification of standard regression inference procedures. Moreover, a large empirical literature, has found these estimates useful for structural analysis (e.g., Bernanke, Boivin, Eliasz (2005), Boivin and Giannone (2006)) and forecasting (see the

\footnotetext{
${ }^{13}$ In effect, we measure financial conditions relative to the setting that would be typical at a particular stage of the business cycle. For example, this approach means that the impact on our FCI of a 250-basis-point spread between the yields of Baa corporate bonds and 10-year Treasuries may be restrictive during an economic expansion and accommodative during a recession.
} 
surveys Stock and Watson (2006) and Eickmeier and Zielger (2008) surveys). Motivated by these results, we will consider least squares estimates of $F$.

The details of our calculations are as follows. Each of the variables listed in Table 4.1 is transformed as indicated in the fourth column in the table (differenced, log-differenced, etc.), and then standardized to have mean zero and unit variance. Each series was then regressed on current and two lagged values of growth in real GDP and inflation (constructed from the GDP price deflator). The residuals from these regressions, say $\hat{v}_{i t}$, are estimates of $v_{i t}$. The factors are then estimated by least squares. That is, $\hat{F}_{t}$ solves $\min _{\left\{\lambda_{i}\right\},\left\{F_{t}\right\}} \sum_{i, t} \hat{v}_{i t}-\lambda_{i}{ }^{\prime} F_{t}{ }^{2}$. The unbalanced panel nature of our dataset is accommodated by summing over non-missing observations. ${ }^{14,15,16}$

Solving the least squares requires that $k$, the number elements in $F$, be specified. In the balanced panel model, Bai and $\mathrm{Ng}$ (2002) propose estimators of $k$ based on the minimized sum of squared residuals (equivalently the maximized average $R^{2}$ ) that results from different value of $k$. The columns labeled $R^{2}$ in Table 4.1 shows how the $R^{2}$ for each indicator varies as $k$ increases from $k$ $=0$ factors (so that only $Y$ is included in the regression) to $k=4$ factors. As $k$ increases from 0 to 4, the average $R^{2}$ (shown in the last row of Table 4.1) increases steadily from 0.29 to 0.65 , suggesting considerable uncertainty in the appropriate value of $k$. Our examination of the fits for the individual series suggested that substantial differences between the fit of the 1-factor and 2factor models for several series, but less substantial differences between the 2-factor and 3- or 4factor fits. Because of this uncertainty, we will consider 1, 2, and 3 factor models in our empirical work.

The final column of Table 4.1 shows the estimated values of of the $\lambda_{i}$ s for the one-factor model. In this case, $\hat{F}_{t}$ is the financial conditions index, and the weight that each financial indicator $\mathrm{i}$ has in the index is proportional to its lambda coefficient. Figures 4.2 and 4.3 show rankings of the indicators by their lambda values. In Figure 4.2 the ranking is by the absolute values of the lambdas, and in Figure 4.3 it is by the actual values. In about half the cases, lambda is negative, indicating a worsening of financial conditions when the indicator increases. This was generally the case for interest rates and spreads, for example. Positive lambdas (where an increase

\footnotetext{
${ }^{14}$ When the panel is balanced, the solution to the least squares problem provides the principal components of $\hat{v}_{i t}$ which can be computed as the eigenvectors of the sample covariance matrix. In the unbalanced panel, iterative methods can be used to find the least squares solution.

${ }^{15}$ Because $\lambda_{i}{ }^{\prime} F_{t}=\lambda_{i}{ }^{\prime} H^{-1} H F_{t}$ for any non-singular matrix $H$, only the column space of the factors can be identified from the data, and so an arbitrary normalization is imposed on the least squares problem. However, only the column space of $F_{t}$ matters for our predictive regressions (the fitted value from a regression of $y$ onto $F$ is the same as the fitted value from the regression of $y$ onto $H F$ ), so the normalization has no effect on the forecasts.

${ }^{16}$ We carried out estimation of the factors for all dates in which we have data on 11 or more financial indicators.
} 
indicates an improvement in financial conditions) generally prevailed among credit flows and asset prices.

\section{EVALUATION OF THE NEW FINANCIAL CONDITIONS INDEX}

In this section, we evaluate our new FCI by first seeing how well it predicts the growth of economic activity relative to the AR model, the five single-variable indicators and the existing financial conditions indexes. We also assess the extent to which the wider coverage of our index and the econometric enhancements used in constructing the new index improved its predictive performance. The breadth of the new index allows us to consider whether some types of financial variables do better than others by assessing the relative predictive performance of various subsets of the included variables. Next, we consider factors that may have contributed to the pervasive finding of forecasting instability among FCIs, including our new one. Finally, we review what the index portends for the period ahead in 2010.

\subsection{Prediction Tests with New FCI}

The one-factor variant of our FCI is shown in Figure 5.1. The series is standardized to have mean zero and unit standard deviation over the sample period, so that it is measured in standard deviation units. With one notable exception, the new FCI follows a pattern that is broadly similar since the early 1990s to those we reviewed in Figure 2.2: both showed a substantial deterioration in financial conditions near the start of the millennium and more recently, with the recent move being somewhat more severe. Both also show a substantial rebound over the past year from crisis lows. The one notable exception is that most recently (in the second half of 2009, our index shows a substantial deterioration whereas the alternative FCIs did not. We will discuss the reasons for this deterioration, an interesting result, at the end of this section. ${ }^{17}$ Going back further, our index showed substantial deteriorations in the mid-1970s and early 1980s, both periods of severe recession, and an impressive spike down in 1987 coinciding with the stock market crash in October of that year.

How well does the new index predict economic activity? Table 5.1 summarizes the pseudo-outof-sample forecasting results based on regression models with one, two and three factors. The results are shown in the same format as we discussed for Tables 3.2 and 3.3 (the data entries are the average relative RMSEs using those for the AR models in Table 3.2 as the benchmark). For purposes of comparison, the table also shows the average prediction errors of the AR model,

\footnotetext{
${ }^{17}$ To update our FCI through the fourth quarter of 2009, we estimated a number of series obtained from the Flow of Funds, as described in the data Annex.
} 
representative single variable and existing FCI models (the S\&P 500 and the KCFSI) from Table 3.2, as well as the averages across the single variables and all the existing FCIs we surveyed.

The key results can be summarized as follows:

- The one-factor variant generally performed at least as well as the two- and three-factor versions. Evidently, while more than a single factor is needed to capture the comovement in the 45 financial variables, only the dominant factor helps forecast future real activity. In what follows, we focus on the one-factor version.

- The one-factor FCI generally tracked future GDP growth better than the AR model - this was especially so during the recent downturn as evident in Table 5.1 and Figure 5.2 (which compares the new FCI and AR predictions of GDP growth). However, the FCI substantially underperformed the AR model during the late 1990s, a period when financial conditions appeared to be worsening but economic growth was robust.

- The new FCI did better than the average single financial indicator in most subperiods, including both the period of the early 1990s and the past decade. It also outperformed the best of the single-factor indicators, the stock market index, over the past five years, but underperformed significantly in a couple of the earlier subperiods. These patterns are evident both in Table 5.1, which compares prediction errors averaged across activity variables and in Figures 5.3a and 5.3b, which show the predicted and actual rates of real GDP growth using the new FCI, the S\&P500 and the existing FCIs.

- Our FCI did somewhat better than other FCIs over three of the four subperiods for which we have results for both sets, but worse during one (the second half of the 1990s).

- Like the other FCIs, our new FCI performed noticeably better after 2000, especially over the most recent five-year period, than it did earlier.

While constructive, these findings cause us to raise several notes of caution. First, the variability of the results over time, with noticeable degradation of relative performance in the late 1980s and latter 1990s, is once again indicative of instability in the relationship between financial conditions and real economic activity. Second, the relatively poor performance of our FCI during the second half of the 1990s in particular suggests that that period merits closer inspection. Third, the better performance during the most recent five years (relative to both the average of the alternative FCIs and KC Fed's index as representative of one of the better performing FCIs) may reflect selection bias in our choice of variables to include in the index: naturally, our selection was governed in part by an understanding of the types of financial variables that were used for monitoring and measuring the recent financial crisis. In this sense, we did not seek to mitigate observer bias.

\subsection{Testing the new FCI's enhancements of the existing technology}


The key features of our FCI that distinguish it from extant FCIs are (1) its broader coverage of existing and more recent financial variables, including indicators other than rates, spreads and asset prices, (2) the use of unbalanced panel estimation techniques to substantially lengthen the history of the FCI, and (3) the purging of financial variables of macroeconomic influences (represented by $\mathrm{A}(\mathrm{L}) Y_{t}$ in equation 2 , Section 4.2 above) .

To gauge the effects of these enhancements, we ran prediction tests with several different versions of the new FCI, including a (nearly) balanced panel variant, a decomposition of the index by type of financial variable, and a version that was not purged of macroeconomic influences. The results of these tests are presented in Table 5.2.

Balanced panel. We constructed a variant of our new FCI that limited the financial variables included to those with histories going back to at least 1980 (that is, 29 of the 45 variables), so that the panel was "balanced" back to 1980 but not before. The relative predictive performance of this variant provides some indication of how increasing the number of financial variables in the index, especially in more recent years, may have affected new FCI's performance.

The baseline new FCI outperforms the narrower, balanced panel variant over the past two decades on average, including the most recent period, suggesting meaningful gains from the wider coverage. However, during the 1980 s, the balanced panel variant outperformed signficantly.

Decomposition tests. The richness of the coverage of our FCI across a variety of types of financial variables allows us considerable latitude to test whether some types of variables do better than others in predicting movements in economic activity. Table 4.1 groups the 45 financial series underlying our FCI into five categories (interest rate levels and spreads (15 series), asset prices ( 5 series), stock and flow quantities (16 series), surveys ( 7 series), and $2^{\text {nd }}$ moment or risk measures ( 3 series)). Figure 5.4 decomposes the FCI into components associated with variables in these categories. ${ }^{18}$ A cursory inspection of the panels in this figure indicates that historically, interest rate spreads have been the most important source of movement of our FCI. They explain most of the steady decline in the FCI during the later 1990s and more recently. In the most recent period of the financial crisis, all five categories contributed to the decline in our FCI.

The results shown in Table 5.2 summarize our forecast tests for a slightly more nuanced decomposition of the individual series, where the interest rate or spread variables have been subdivided into liquidity indicators and credit indicators. The specific indicators in each

18 At each date, the FCI is a linear combination of the 45 variables, where the weights change through time because of the unbalanced nature of the data set. Each panel in Figure 5.4 shows the contribution to the overall FCI of the group of variables indicated in the headline. 
category are listed in the appendix. The results indicate that no single component stood out as consistently better: Some outperformed in some subperiods and others in other subperiods. The overall FCI often did better than any of its major components. This was especially true during the most recent period when the overall FCI outperformed each of the separate categories (as well as the star performer among individual financial variables, the stock market index) by wide margins. This result suggests that there are significant benefits to be gained from pooling a large set of financial indicators. But the force of this observation may be weakened by the aforementioned selection bias in our construction of the new FCI. Moreover, in at least one subperiod (the latter 1990s), the overall index did significantly worse than its subcomponents.

Purging macro influences. Our third test entailed using the index constructed with all 45 variables, but where the input variables were not purged of the effects of movements in economic activity (GDP growth and inflation--i.e., those effects represented by $\mathrm{A}(\mathrm{L}) Y_{t}$ in equation 2, as discussed in Section 4.2 above). The second to last row in each half of Table 5.2 shows prediction results for the unpurged index. A comparison with the top row of each table indicates that purging the underlying variables of macro influences yields noticeably better forecasting results during the early 1990s and over the past ten years, especially the most recent period. But purging yields worse results (than the unpurged variant) during other periods. ${ }^{19}$

Figure 5.5 displays the effects of purging the FCI of macro influences in a bit more detail. During the mid-1970s and early 1980s the unpurged index was significantly more negative than the purged index. That is, the financial indicators (particularly the interest rates and spreads, which dominate the index in this period) suggested severe disruptions in the financial sector, but much of this could be explained by the prevailing level of real activity and inflation. Looking at the most recent (2009:Q4) values of the indexes, the unpurged index is essentially neutral, while the purged index shows a significant drop from 2009:Q2 to 2009:Q4. The unpurged index shows that, viewed in isolation, financial conditions are near their average values. In contrast, the purged index suggests that, conditional on the pace of the recovery in the second half of 2009, financial conditions remain a drag on future real activity.

Purging the funds rate. Our fourth test was to include the federal funds rate in the list of macro influences to be purged before constructing our FCI. The resulting FCI is shown graphically in Figure 5.6, and the forecast performance is shown in the last row of each half of Table 5.2. The results show that the forecast performance of the alternative FCI is generally not too different

\footnotetext{
19 There were two local minima in the least squares function defining the non-purged FCI. The index corresponding to the lowest of these had unusual variation patterns over the last decade in the sample while the index corresponding to the largest of the two local minima behaved much like the FCI plotted in Figure 5.1. Moreover, the index associated with the larger of two minima produced more accurate forecasts than the other index. For these reasons we used the index associated with the largest of the two local minima as the non-purged index. The purged FCI corresponds to usual principal component.
} 
from our benchmark FCI; it is modestly worse for most subperiods, but less bad for the 19951999 period.

Combined with the poor performance of the fed funds rate in the single-indicator results shown in Tables 3.1 and 3.2, these results suggest that pure monetary shocks contributed relatively little to the prediction of future economic activity during our sample period - a result consistent with structural VAR exercises that show that monetary policy shocks explain little of the variance of output (e.g., Christiano, Eichenbaum, and Evans (1999)). Consequently, purging the FCI of their influence has only a slight impact on its utility as a forecasting tool. In light of the perceived utility of the term structure as an economic predictor, this result may come as somewhat of a surprise. But it is also consistent with our finding (Section 3, Table 3.2) that the term structure has not been particularly useful as a single-variable financial indicator in predicting economic activity since the mid-1980s.

At the same time, there is evidence that monetary policy actions have been substantially more important in specific episodes. Figure 5.6 shows that some of the biggest supportive effects from the funds rate - i.e., the biggest gaps between the purged and unpurged FCI - occurred around the stock market crash of 1987 and during the recent financial crisis. Moreover, our exclusive focus on the federal funds rate as a gauge of monetary policy probably understates policy's impact during these episodes. In the fall of 1987, for example, the FOMC's statement affirming its "readiness to serve as a source of liquidity" to the financial system may have been more important in cushioning the impact of the crash than the 50-basis-point cut in the federal funds rate target. Similarly, in late 2008 and early 2009, the sharp cut in the funds rate to near zero percent was only one aspect of the Fed's response to the crisis. Other measures - including the various liquidity facilities, the asset purchases, and the "stress test" for major banks - were also very important. If we were able to include these adequately in our index, we would probably find an even bigger impact from monetary policy during crisis episodes.

\subsection{Possible sources of instability}

Our tests indicate that our new FCI is a more reliable predictor of activity during recent periods, especially the crisis episode, but was less so earlier. This instability may be cause for concern. It points to the need to understand both the evolution of financial conditions and its underlying causes in order to use FCIs effectively. For example, we find that purging the index of macroeconomic influences yields substantially better results (than not purging) in some periods (the early 1990s and the 2000s, especially most recently), but worse results in other periods. The periods of success have been associated with episodes of considerable financial distress - the S\&L crisis of the early 1990s, the dot-com bubble burst of the early 2000s, and the more severe financial crisis in recent years. While these episodes may have been triggered by monetary policy restraint, the scale of turmoil was not closely related to the degree of restraint. 
Our discussion in Section 2.1 noted the extent to which FCIs historically have been considered as a way to broaden measurement of the monetary transmission mechanism. But it also noted that at times, exogenous influences other than changes in monetary policy can be the dominant driver of broad financial conditions. This pattern has prevailed in recent years, and may help to explain why several FCIs functioned better more recently. To illustrate this point empirically, Figure 5.7 shows the path of the new FCI and the fed funds target in recent decades. The shading in Figure 5.7 denotes periods of Fed policy easing and the non-shaded areas periods of Fed tightening. Until the recent episode, financial conditions generally deteriorated when the Fed tightened, and improved when the Fed eased. During the recent crisis, however, financial conditions tightened dramatically even as the Fed eased aggressively. The episodes of Fed tightening are summarized in Figure 5.8, which shows the maximum, minimum, and average paths of the FCI during periods of Fed tightening prior to the most recent one (which began in 2004). ${ }^{20}$ The path of the FCI beginning in 2004 does show a slight deterioration of financial conditions as the Fed tightened, but the response is unusually weak. The results for easing cycles summarized in the same format in Figure 5.9 are more dramatic: In the most recent cycle, the FCI worsens for much of the period more than in any prior easing cycle.

These observations suggest that financial conditions indexes do better in predicting activity during periods dominated by exogenous financial disturbances. This pattern favors the strategy of purging macroeconomic influences from financial conditions measures in order to focus on the pure financial shocks.

\subsection{What our FCI tells us about the period ahead.}

We noted at the outset of this section that our FCI shows an evolution of financial conditions after the spring of 2009 that differs from the pattern of other FCIs. Whereas the existing FCIs show the current level of financial conditions to be back at or slightly better than "normal" levels, our index has deteriorated substantially over the past two quarters. Indeed, it has retraced more than a third of the sharp rebound that had occurred earlier in 2009. This setback suggests that financial conditions are somewhat less supportive of growth in real activity than suggested by other FCIs.

How do we explain this result? We cannot rule out statistical variance in the data around a turning point as a contributing factor. However, there may very well be an important behavioral explanation for the retreat of financial conditions. To show this, Figure 5.10 decomposes the changes from 2009:Q2 to 2009:Q4 in both the unpurged and purged versions of our FCI into the five main indicator categories: interest rates, asset prices, quantitative indicators, surveys, and second moments. On an unpurged basis, the interest rate, survey, and second moment indicators

\footnotetext{
${ }^{20}$ The maximums and minimums are across all cycles (except for the most recent one) for any given period.
} 
improved, although some of this improvement was offset by a deterioration elsewhere. ${ }^{21}$

However, on a purged basis, the interest rate and second moment indicators show only a modest improvement, while the asset price, survey and especially quantitative indicators deteriorated substantially. The deterioration in the quantitative indicators was concentrated in non-mortgage ABS issuance, commercial mortgage debt, and repo loans.

By way of interpretation, we see two main reasons for the difference between the new FCI and other measures: 1) the broader range of indicators included and 2) the purging of the direct impact of the business cycle on financial conditions. Regarding 1), the improvement in financial conditions since the spring of 2009 has been concentrated in indicators that are included in virtually all financial conditions indexes, namely interest rates, credit spreads, and stock prices. In contrast, several components of our FCI that have not been previously included - particularly quantity indicators related to the performance of the "shadow banking system" such as ABS issuance and repo loans, as well as total financial market cap and surveys of bank lending standards - failed to improve much (or at least anywhere near as much as normally could be anticipated during an economic recovery). This is seen in Table 5.3 and Figure 5.11. The table shows the top contributors (across components of our FCI) to the decline in the overall FCI during the second half of 2009. ABS issuance is clearly at the top of the list. Figure 5.11 indicates that ABS issuance remained relatively subdued during the second half of 2009. This suggests that the continued woes of the shadow banking system could continue to weigh on the pace of the recovery, despite the recovery in more traditional measures of financial conditions.

Regarding the second factor, it is noteworthy that the purged FCI has deteriorated relative to the unpurged index. This gap means that the evolution of financial conditions since mid-2009 has fallen short of past experience in the presence of a GDP rebound. In other words, any improvement of financial conditions was more than accounted for by the impact of past economic growth. Consequently, the implications of current financial conditions for future growth appear somewhat less favorable than traditional FCIs may imply.

\section{CONCLUDING REMARKS}

In this paper, we studied financial condition indexes and find that they can help predict economic activity. Among single-variable indicators, a broad stock market index outperforms as a predictor over the next two to four quarters. A representative sample of available FCIs typically

\footnotetext{
${ }^{21}$ It may seem surprising that the asset price indicators show no net improvement, given the large increase in equity prices since the spring. However, note that our asset price indicators generally enter the FCI as (log) changes rather than levels, and the pace of asset price improvement has slowed since the spring.
} 
outperformed the single-variable indicators (yield curve, credit spreads, and so on), but some did not outperform the stock market index.

We focused on improving the predictive capabilities of FCIs by: (1) expanding the data history; (2) expanding the data coverage; and (3) disentangling macroeconomic and policy influences from pure financial shocks. Accordingly, we developed and tested a new FCI that addresses these matters. While our analysis was done at a quarterly frequency, it would be possible to construct a broad FCI at a monthly interval, using both monthly and quarterly data. One notable disadvantage of the new FCI is that its size and estimation make it more cumbersome to update and use.

In forecasting tests, the new FCI outperformed a variety of alternative measures in recent years, but not so during earlier periods. In analyzing this performance, we found that both purging the FCI of macroeconomic influences and expanding coverage to a wide number and variety of variables contributed to its relatively better performance in recent years. The exclusion of macroeconomic influences contributed to this improvement somewhat more than the expansion of coverage. The overall index performed noticeably better in recent years than any of its major subcomponents (rates/spreads, asset prices, surveys, quantities, and so on).

Our finding that the relative predictive performance of our new FCI was unstable over time reconfirmed earlier findings of instability for an array of financial indicators. Our index seemed to work especially well in times of unusual financial stress emanating from within asset markets. Purging our index of macroeconomic influences seemed to be most effective in improving its performance during these periods.

Finally, given the nature of the recent financial and economic crisis, gauging the path of financial conditions overall as they bear on prospects for economic activity will be an especially important ingredient in the economic forecasts prepared for policymakers and investors alike. The estimated level of our FCI as of the end of 2009 pointed to credit conditions that remained somewhat tighter than the norm, implying a continuing, if modest, drag from overall financial conditions on economic growth during 2010. 


\section{References}

Ando, A., and F. Modligliani (1963), "The Life-Cycle Hypothesis of Saving: Aggregate Implications and Tests," American Economic Review 53, 55-84.

Bai, J., and S. Ng (2002), "Determining the Number of Factors in Approximate Factor Models," Econometrica, 70, 191-221. (2008), "Large Dimensional Factor Analysis," Foundations and Trends in Econometrics, 3(2): 89-163.

Beaton, K., R. Lalonde, and C. Luu (2009), "A Financial Conditions Index for the United States," Bank of Canada Discussion Paper, November.

Bernanke, B. (1990), "On the Predictive Power of Interest Rates and Interest Rate Spreads," New England Economic Review, November, pages 51-68.

Bernanke, B.S., J. Boivin, and P. Eliasz (2005), "Measuring the Effects of Monetary Policy: A Factor-Augmented Vector Autoregressive (FAVAR) Approach," Quarterly Journal of Economics, 120, 387-422.

Boivin, J., and M. Giannoni (2006), "DSGE Models in a Data-Rich Environment," NBER Working Paper no. 12772, December.

Boivin, J., M. Kiley, and F. Mishkin (2009), "How Has the Monetary Transmission Mechanism Evolved Over Time?" prepared for the third Handbook of Monetary Economics; presented at the Federal Reserve Conference on Key Developments in Monetary Policy, October 9, 2009.

Brunnermeier, M. and Y. Sannikov (2009), "A Macroeconomic Model with a Financial Sector," working paper.

Christiano, L.J., M. Eichenbaum, and C.L. Evans (1999), "Monetary Policy Shocks: What Have We Learned and to What End?", in J.B. Taylor and M. Woodford (eds), Handbook of Macroeconomics, Vol. 1A, Amsterdam: Elsevier.

D'Antonio, P., Appendix, pages 26-28, in DiClemente, R. and K. Schoenholtz (September 26, 2008), "A View of the U.S. Subprime Crisis," EMA Special Report, Citigroup Global Markets Inc.

Dudley, W., and J. Hatzius (June 8, 2000). The Goldman Sachs Financial Conditions Index: The Right Tool for a New Monetary Policy Regime. Global Economics Paper No. 44.

Dudley, W., J. Hatzius, and E. McKelvey (April 8, 2005). Financial Conditions Need to Tighten Further. US Economics Analyst, Goldman Sachs Economic Research. 
Eickmeier, S. and C. Ziegler (2008), "How successful are dynamic factor models at forecasting output and inflation? A meta-analytic approach," Journal of Forecasting, 27(3), 237-265.

English, W., K. Tsatsaronis and E. Zoli (2005), "Assessing the predictive power of measures of financial conditions for macroeconomic variables," published in "Investigating the relationship between the financial and the real economy" (BIS Papers No 22, April 2005).

Estrella, A., and G. Hardouvelis (1991), “The term structure as a predictor of real economic activity," Journal of Finance 46, 555-576.

Estrella, A., and F, Mishkin (1998), "Predicting U.S. Recessions: Financial Variables as Leading Indicators," Review of Economics and Statistics 80, 45-61.

Freedman, C. (1994). The use of indicators and of the monetary conditions index in Canada. In Balino, T.J.T. and Cottarelli, C. (eds), Frameworks for Monetary Stability: Policy Issues and Country Experiences, IMF, Washington, D.C.

Gertler, M.and N. Kiyotaki (2009), "Financial Intermediation and Credit Policy in Business Cycle Analysis," prepared for the third Handbook of Monetary Economics; presented at the Federal Reserve Conference on Key Developments in Monetary Policy, October 9, 2009.

Gilchrist, S., V. Yankov and E. Zakrajsek, "Credit Market Shocks and Economic Fluctuations: Evidence from Corporate Bond and Stock Markets," Journal of Monetary Economics, May 2009.

Goodhart, C. and B. Hofmann (February 2001), "Asset Prices, Financial Conditions, and the Transmission of Monetary Policy," FRB San Francisco, Paper prepared for the conference on 'Asset Prices, Exchange Rates, and Monetary Policy' Stanford University, March 2-3, 2001.

Guichard, S. and D. Turner (September 2008), "Quantifying the effect of financial conditions on US activity," OECD Economics Department Working Papers.

Hakkio, C. S. and W. R. Keeton (2Q 2009), "Financial Stress: What is it, how can it be measured, and why does it matter?" Federal Reserve Bank of Kansas City Economic Review.

Harvey, C. (1988), "The Real Term Structure of and Consumption Growth," Journal of Financial Economics, 22, pp. 305-333.

Hooper, P., T. Mayer and T. Slok (June 11, 2007). "Financial Conditions: Central Banks Still Ahead of Markets," Deutsche Bank, Global Economic Perspectives.

Hooper, P., T. Slok and C. Dobridge (January 6, 2010), "Improving Financial Conditions Bode Well for Growth,” Deutsche Bank, Global Economic Perspectives.

Jorgenson, D. (1996), Capital Theory and Investment Behavior, Cambridge, MIT Press. 
Friedman, B. and K. Kuttner (1992), "Why Does the Paper-Bill Spread Predict Real Economic Activity?" in Business Cycles, Indicators and Forecasting, Stock, J. and M. Watson, eds., Chicago: University of Chicago Press.

Laurent, R. (1989), “Testing the Spread,” Federal Reserve Bank of Chicago, Economics Perspectives, 12:1, pp. 3-14.

Montagnoli, A. and O. Napolitano (March 2006), "Financial Condition Index and interest rate settings: a comparative analysis," WP No. 8.2005, University of Naples, Italy.

Rosenberg, M. (December 3, 2009), “Financial Conditions Watch,” Bloomberg.

Stock, J. and M. Watson, (1989), "New Indexes of Coincident and Leading Economic Indicators," in Blanchard O. and S. Fischer (eds.), NBER Macroeconomics Annual (Cambridge, MA: MIT), 352-94.

(2003), "Forecasting Output and Inflation: The Role of Asset Prices," Journal of

Economic Literature, Vol. 41, No. 3, 788-829.

(2006), "Forecasting with Many Predictors," ch. 6 in Handbook of Economic

Forecasting, ed. by Elliott, G., C. Granger, and A. Timmermann, Elsevier, 515-554.

(2007), Introduction to Econometrics, Second Edition, Pearson, Addison-Wesley:

Boston.

(2010), "Dynamic Factor Models," Prepared for the Oxford Handbook of

Economic Forecasting, M. Clements and D. Hendry (eds.), Oxford University Press.

Swiston, A. J. (June 2008). “A U.S. Financial Conditions Index: Putting Credit Where Credit is Due," IMF Working Paper.

Zarnowitz, V. (1992). “Composite Indexes of Leading, Coincident, and Lagging Indicators,” in Zarnowitz, V. (ed.) Business Cycles: Theory, History, Indicators and Forecasting, University of Chicago Press, 316-356. 


\section{Appendix:}

Variables used in the subindexes in Table 5.2:

Price Subindex:

\begin{tabular}{|l|l|}
\hline 1 & $10-$ Year Treasury Note Yield at Constant Maturity \\
\hline 2 & FedFunds/3monthTBill Spread \\
\hline 3 & 2YrT-note/3monthTbill Spread \\
\hline 4 & 10YrT-note/3monthTbill Spread \\
\hline 5 & Baa/10yr T-note Spread \\
\hline 6 & High Yield / Baa Spread \\
\hline 7 & Auto finance company loan rate, new Car/Two-yr Treasury Spread \\
\hline 8 & 30-yr Conventional mortgage/ 10yrTBond Spread \\
\hline 9 & Jumbo/30yr Conventional Spread \\
\hline 10 & TED Spread (Using Constant Maturity T-bill) \\
\hline 11 & 3-month LIBOR/OIS \\
\hline 12 & Bank rate on new Car Loans, 48-month/Two-year Treasury Spread \\
\hline 13 & Bank rate on Personal Loans, 24-month/Two-year Treasury Spread \\
\hline 14 & Citigroup Bond Yields:Credit $\{$ Corp $\}$ Spread/Finance \\
\hline 15 & Banks CDS Spread \\
\hline 16 & Real Broad Trade-Weighted Exchange Value of the US\$ \\
\hline 17 & Wilshire 5000 \\
\hline 18 & Financial Market Cap (percent of S\&P 500) \\
\hline 19 & Loan Performance National House Price Index (SA) \\
\hline 20 & Price of Oil Relative to 2Year MA (PPI Crude Oil) \\
\hline 21 & Correlation of Returns on Equities and Treasuries \\
\hline 22 & Idiosyncratic Bank Stock Volatility \\
\hline 23 & Monthly Average VIX \\
\hline
\end{tabular}

Quantity Subindex:

\begin{tabular}{|l|l|}
\hline 1 & Bank Credit: All Commercial Banks (SA) \\
\hline 2 & Commercial Paper Outstanding:All Issuers (SA) \\
\hline 3 & Commercial Paper Issuance (Relative to 24Month MA) \\
\hline 4 & ABS Issuance (Relative to 24Month MA) \\
\hline 5 & CMBS Issuance (Alert Database) (Relative to 24Month MA) \\
\hline 6 & Money Stock:MZM \{Zero Maturity\} (SA) \\
\hline 7 & State \& local Government:Liability:Credit Market Instruments (SA) \\
\hline 8 & Nonfederal Sectors:Liability:Credit Market Debt Outstanding (SA) \\
\hline 9 & Private Nonfinancial Debt, SA \\
\hline 10 & Total Finance:Liabilities:Security RPs (NSA) \\
\hline 11 & ABS Issuers:Assets; Consumer Credit (NSA) \\
\hline 12 & ABS Issuers:Asset; Mortgages on 1-4 Family Structures (NSA) \\
\hline 13 & ABS Issuers:Asset; Commercial Mortgages (NSA) \\
\hline 14 & Total Non-monrtgage ABS Issuance (NSA) Relative to 8Q MA) \\
\hline 15 & Broker Dealer Leverage \\
\hline
\end{tabular}


Survey Subindex:

\begin{tabular}{|l|l|}
\hline 1 & NFIB:\%Reporting that Credit Was Harder to Get Last Time, Net (SA) \\
\hline 2 & $\begin{array}{l}\text { Michigan Survey:Interest Rates/Credit Reason Good/Bad Conditions for Buying Large } \\
\text { HH Goods Spread }\end{array}$ \\
\hline 3 & $\begin{array}{l}\text { Michigan Survey:Interest Rates/Credit Reason for Good/Bad Conditions for Buying } \\
\text { Houses Spread }\end{array}$ \\
\hline 4 & $\begin{array}{l}\text { Michigan Survey:Interest Rates/Credit Reason for Good Less Bad Conditions for Buying } \\
\text { Autos Spread }\end{array}$ \\
\hline 5 & FRB Sr. Of. Banks Tightening C\&I Loans to Large Firms (\%) \\
\hline 6 & FRB Sr. Of.:Banks Tightening C\&I Loans to Small Firms (\%) \\
\hline 7 & FRB Sr. Of.:Banks Willingness to Lend to Consumers (\%) \\
\hline
\end{tabular}

Liquidity Subindex:

\begin{tabular}{|l|l|}
\hline 1 & FedFunds/3monthTBill Spread \\
\hline 2 & 2YrT-note/3monthTbill Spread \\
\hline 3 & 10YrT-note/3monthTbill Spread \\
\hline
\end{tabular}

Credit Subindex:

\begin{tabular}{|l|l|}
\hline 1 & Baa/10yr T-note Spread \\
\hline 2 & High Yield/Baa Spread \\
\hline 3 & Auto finance company loan rate, New Car/2Yr T-note Spread \\
\hline 4 & 30-yr Conventional mortgage/ 10yr T-note Spread \\
\hline 5 & Jumbo/30yr Conventional Spread \\
\hline 6 & Citigroup Bond Yields: Credit \{Corp $\}$ \\
\hline 7 & Banks CDS Spread \\
\hline 8 & Bank rate on new car loans, 48-month/Two-year Treasury Spread \\
\hline 9 & Bank rate on personal loans, 24-month/Two-year Treasury Spread \\
\hline
\end{tabular}


Data Availability:

The majority of our data are publicly available and are included in the paper's replication files. However, some series are from proprietary sources; in these cases, the table below indicates the source, series name (where applicable), and calculation.

\begin{tabular}{|c|c|c|c|}
\hline Description & Data Source & Series 1 & Series 2 \\
\hline High Yield / Baa Spread & Haver Analytics & FMLHY@USECON & FBAA@USECON \\
\hline $\begin{array}{l}\text { Jumbo/30yr Conventional } \\
\text { Spread }\end{array}$ & $\begin{array}{l}\text { Bloomberg/ Haver } \\
\text { Analytics }\end{array}$ & ILMJNAVG Index & FMC@USECON \\
\hline 3-month LIBOR/OIS Spread & $\begin{array}{l}\text { Haver Analytics/ } \\
\text { Bloomberg (DB) }\end{array}$ & FLOD3@USECON & USSOC CMPT Curncy \\
\hline $\begin{array}{l}\text { Bank rate on new car loans, } 48 \\
\text { months/Two-year Treasury } \\
\text { Spread }\end{array}$ & Haver Analytics & FFINC@USECON & FCM2@USECON \\
\hline $\begin{array}{l}\text { Credit spread Corporate/ } \\
\text { Financial Sector (Citi) }\end{array}$ & Haver Analytics & SYCF@USECON & SYCT@USECON \\
\hline Banks CDS Spread & Bloomberg & GCDS & \\
\hline Wilshire 5000 stock price index & Bloomberg & W5000FLT & \\
\hline $\begin{array}{l}\text { Financial Market Cap (percent } \\
\text { of S\&P 500) }\end{array}$ & Compustat & n.a. & \\
\hline $\begin{array}{l}\text { Loan Performance National } \\
\text { House Price Index (SA) }\end{array}$ & Haver Analytics & USLPHPIS@USECON & \\
\hline $\begin{array}{l}\text { ABS Issuance (Relative to } 24 \\
\text { Month MA) }\end{array}$ & Bloomberg & IABS & \\
\hline $\begin{array}{l}\text { CMBS Issuance (Alert } \\
\text { Database) (Relative to } \\
\text { 24Month MA) }\end{array}$ & SIFMA & n.a. & \\
\hline $\begin{array}{l}\text { Total Non-mortgage ABS } \\
\text { Issuance (NSA Relative to } 8 Q \\
\text { MA) }\end{array}$ & SIFMA & n.a. & \\
\hline $\begin{array}{l}\text { NFIB: \% Reporting that credit } \\
\text { was harder to get last time, Net } \\
\text { (SA) }\end{array}$ & Haver Analytics & NFIB20@SURVEYS & \\
\hline $\begin{array}{l}\text { Michigan: Interest rates/credit } \\
\text { reason good/bad conditions for } \\
\text { buying Large HH Goods } \\
\text { Spread }\end{array}$ & Haver Analytics & MCCPLW2@UMSCA & MCCPLB3@UMSCA \\
\hline $\begin{array}{l}\text { Michigan: Interest rates/credit } \\
\text { reason for good/bad conditions } \\
\text { for buying houses spread }\end{array}$ & Haver Analytics & MCCPHW2@UMSCA & MCCPHB3@UMSCA \\
\hline $\begin{array}{l}\text { Michigan: Interest rates/credit } \\
\text { reason for good less bad } \\
\text { conditions for buying autos } \\
\text { spread }\end{array}$ & Haver Analytics & MCCPVW2@UMSCA & MCCPVB3@UMSCA \\
\hline
\end{tabular}


Table 3.1:Results from In-Sample Regressions

1961:1 - 2006:IV

$$
y_{t+h}-y_{t}=\beta_{0}+\sum_{i=1}^{4} \phi_{i} \Delta y_{t+1-i}+\sum_{i=1}^{4} \gamma_{i} x_{t+1-i}+u_{t+i}
$$

(a) $h=2$

\begin{tabular}{|l|c|c|c|c|c|c|c|c|c|c|c|c|}
\hline & \multicolumn{3}{|c|}{ Real GDP } & \multicolumn{4}{c|}{$I P$} & \multicolumn{3}{c|}{ Employment } & \multicolumn{3}{|c|}{ Unemployment Rate } \\
\hline $\begin{array}{l}\text { Financial } \\
\text { Indicator }\end{array}$ & $R_{x / \Delta y}^{2}$ & $F$ & $Q L R$ & $R_{x / \Delta y}^{2}$ & $F$ & $Q L R$ & $R_{x / \Delta y}^{2}$ & $F$ & $Q L R$ & $R_{x / \Delta y}^{2}$ & $F$ & $Q L R$ \\
\hline FedFunds & 0.20 & 11.38 & 6.12 & 0.14 & 8.36 & 3.00 & 0.07 & 7.65 & 3.75 & 0.11 & 5.08 & 5.23 \\
& & $(0.000)$ & $(0.002)$ & & $(0.000)$ & $(0.212)$ & & $(0.000)$ & $(0.078)$ & & $(0.000)$ & $(0.008)$ \\
\hline Term & 0.08 & 4.08 & 9.03 & 0.05 & 2.85 & 8.21 & 0.03 & 3.75 & 7.36 & 0.12 & 5.50 & 4.48 \\
Spread & & $(0.003)$ & $(0.000)$ & & $(0.022)$ & $(0.000)$ & & $(0.005)$ & $(0.000)$ & & $(0.000)$ & $(0.026)$ \\
\hline Credit & 0.20 & 14.71 & 10.71 & 0.26 & 14.92 & 10.72 & 0.11 & 10.61 & 10.75 & 0.24 & 9.79 & 12.37 \\
Spread & & $(0.000)$ & $(0.000)$ & & $(0.000)$ & $(0.000)$ & & $(0.000)$ & $(0.000)$ & & $(0.000)$ & $(0.000)$ \\
\hline Real M2 & 0.18 & 8.75 & 6.38 & 0.17 & 6.94 & 4.64 & 0.06 & 5.06 & 5.99 & 0.08 & 3.26 & 2.08 \\
& & $(0.000)$ & $(0.001)$ & & $(0.000)$ & $(0.021)$ & & $(0.000)$ & $(0.002)$ & & $(0.011)$ & $(0.567)$ \\
\hline SP500 & 0.09 & 6.72 & 5.83 & 0.16 & 5.55 & 3.81 & 0.09 & 6.47 & 5.50 & 0.15 & 5.83 & 2.57 \\
& & $(0.000)$ & $(0.003)$ & & $(0.000)$ & $(0.072)$ & & $(0.000)$ & $(0.005)$ & & $(0.000)$ & $(0.350)$ \\
\hline
\end{tabular}

(b) $h=4$

\begin{tabular}{|l|c|c|c|c|c|c|c|c|c|c|c|c|}
\hline & \multicolumn{3}{|c|}{ Real GDP } & \multicolumn{4}{c|}{ IP } & \multicolumn{3}{c|}{ Employment } & \multicolumn{3}{c|}{ Unemployment Rate } \\
\hline Financial & $R_{x / \Delta y}^{2}$ & $F$ & $Q L R$ & $R_{x / \Delta y}^{2}$ & $F$ & $Q L R$ & $R_{x / \Delta y}^{2}$ & $F$ & $Q L R$ & $R_{x / \Delta y}^{2}$ & $F$ & $Q L R$ \\
Indicator & & & & & & & & \\
\hline FedFunds & 0.26 & 10.74 & 6.38 & 0.27 & 10.27 & 4.87 & 0.15 & 9.17 & 5.15 & 0.26 & 8.66 & 8.41 \\
& & $(0.000)$ & $(0.001)$ & & $(0.000)$ & $(0.014)$ & & $(0.000)$ & $(0.009)$ & & $(0.000)$ & $(0.000)$ \\
\hline Term & 0.13 & 2.82 & 10.81 & 0.10 & 2.64 & 11.01 & 0.08 & 3.32 & 12.73 & 0.26 & 5.48 & 9.13 \\
Spread & & $(0.024)$ & $(0.000)$ & & $(0.032)$ & $(0.000)$ & & $(0.010)$ & $(0.000)$ & & $(0.000)$ & $(0.000)$ \\
\hline Credit & 0.12 & 10.17 & 11.56 & 0.21 & 12.21 & 21.85 & 0.11 & 8.28 & 16.41 & 0.24 & 10.27 & 19.56 \\
Spread & & $(0.000)$ & $(0.000)$ & & $(0.000)$ & $(0.000)$ & & $(0.000)$ & $(0.000)$ & & $(0.000)$ & $(0.000)$ \\
\hline Real M2 & 0.23 & 7.78 & 9.96 & 0.23 & 6.76 & 6.05 & 0.10 & 4.63 & 8.53 & 0.15 & 2,84 & 2.64 \\
& & $(0.000)$ & $(0.000)$ & & $(0.000)$ & $(0.002)$ & & $(0.001)$ & $(0.000)$ & & $(0.023)$ & $(0.326)$ \\
\hline SP500 & 0.07 & 3.97 & 2.72 & 0.16 & 5.78 & 3.42 & 0.10 & 5.09 & 4.56 & 0.17 & 4.57 & 3.02 \\
& & $(0.003)$ & $(0.297)$ & & $(0.000)$ & $(0.123)$ & & $(0.000)$ & $(0.023)$ & & $(0.001)$ & $(0.207)$ \\
\hline
\end{tabular}

Notes: $R_{x / y}^{2}$ denotes the partial $R^{2}$ for the lags of $x$ conditional on the lags if $y . F$ denotes the $F$-statistic associated with the null hypothesis that all of the $\gamma_{i}$ coefficients are equal to zero, where the $p$-value is shown in parentheses. $Q L R$ is the "sup-Chow" $F$-statistic testing for stability of the $\gamma_{i}$ coefficients ( $p$-value in parentheses). These test statistics using HAC covariance estimators with 2 lags for $h=2$ and 8 lags for $h=4$. 
Table 3.2: Pseudo-out-of sample root mean square forecast errors for $A R$ and single indicator models.

\begin{tabular}{|c|c|c|c|c|c|c|c|c|}
\hline \multicolumn{9}{|c|}{ (a) $h=2$} \\
\hline & $\begin{array}{l}1970 . I- \\
1974 . I V\end{array}$ & $\begin{array}{l}1975 . I- \\
1979 . I V\end{array}$ & $\begin{array}{l}\text { 1980.I - } \\
\text { 1984. IV }\end{array}$ & $\begin{array}{l}\text { 1985.I - } \\
\text { 1989. IV }\end{array}$ & $\begin{array}{l}\text { 1990.I - } \\
\text { 1994. IV }\end{array}$ & $\begin{array}{l}\text { 1995.I - } \\
\text { 1999. IV }\end{array}$ & $\begin{array}{l}\text { 2000.I - } \\
\text { 2004. IV }\end{array}$ & $\begin{array}{l}\text { 2005.I- } \\
\text { EOS }\end{array}$ \\
\hline & \multicolumn{8}{|c|}{ Root MSE for AR Forecasts } \\
\hline GDP & 3.88 & 3.36 & 4.02 & 0.90 & 2.04 & 1.28 & 1.63 & 3.07 \\
\hline Employment & 2.10 & 1.93 & 2.00 & 0.55 & 1.06 & 0.39 & 1.07 & 1.74 \\
\hline IP & 8.70 & 5.09 & 6.73 & 2.43 & 3.26 & 2.21 & 3.51 & 6.73 \\
\hline Unemp Rate & 0.75 & 0.69 & 0.76 & 0.23 & 0.38 & 0.21 & 0.35 & 0.64 \\
\hline \multirow[t]{2}{*}{ Average } & 3.86 & 2.77 & 3.38 & 1.03 & 1.69 & 1.02 & 1.64 & 3.05 \\
\hline & \multicolumn{8}{|c|}{ Relative Root MSE for Fed Funds Model Forecasts } \\
\hline GDP & 1.03 & 1.00 & 0.84 & 1.51 & 1.19 & 1.03 & 1.21 & 1.15 \\
\hline IP & 1.08 & 0.95 & 1.01 & 1.38 & 1.11 & 0.91 & 1.00 & 1.14 \\
\hline Employment & 1.24 & 0.87 & 1.18 & 1.04 & 1.18 & 0.94 & 1.01 & 1.15 \\
\hline \multirow[t]{2}{*}{ Unemp Rate } & 1.09 & 0.95 & 0.97 & 0.97 & 1.15 & 1.08 & 1.14 & 1.19 \\
\hline & \multicolumn{8}{|c|}{ Average Relative Root MSE for Financial Indicator Model Forecasts } \\
\hline Fed Funds & 1.11 & 0.94 & 1.00 & 1.22 & 1.16 & 0.99 & 1.09 & 1.16 \\
\hline Term Spread & 0.86 & 0.94 & 0.96 & 1.71 & 1.13 & 1.21 & 1.07 & 1.08 \\
\hline Short-term Credit Spread & 0.67 & 0.67 & 0.79 & 1.75 & 1.41 & 1.07 & 1.42 & 0.83 \\
\hline Real M2 & 0.65 & 0.96 & 0.99 & 1.67 & 1.27 & 1.13 & 1.39 & 1.19 \\
\hline SP500 & 0.74 & 1.06 & 0.88 & 1.88 & 1.00 & 1.18 & 0.87 & 0.84 \\
\hline Average & 0.81 & 0.92 & 0.92 & 1.65 & 1.19 & 1.11 & 1.17 & 1.02 \\
\hline \multicolumn{9}{|c|}{ (b) $h=4$} \\
\hline & $\begin{array}{l}1970 . I- \\
\text { 1974.IV }\end{array}$ & \begin{tabular}{l|}
$1975 . I-$ \\
$1979 . I V$
\end{tabular} & $\begin{array}{l}1980 . I- \\
\text { 1984. IV }\end{array}$ & $\begin{array}{l}\text { 1985.I - } \\
\text { 1989. IV }\end{array}$ & $\begin{array}{l}\text { 1990.I - } \\
\text { 1994. IV }\end{array}$ & $\begin{array}{l}\text { 1995.I - } \\
\text { 1999. IV }\end{array}$ & $\begin{array}{l}\text { 2000.I - } \\
\text { 2004. IV }\end{array}$ & $\begin{array}{l}2005 . I- \\
\text { EOS }\end{array}$ \\
\hline & \multicolumn{8}{|c|}{ Root MSE for AR Forecasts } \\
\hline GDP & 3.55 & 2.46 & 3.33 & 0.99 & 1.75 & 1.01 & 1.41 & 3.17 \\
\hline Employment & 2.13 & 1.78 & 2.20 & 0.65 & 1.33 & 0.38 & 1.46 & 2.52 \\
\hline IP & 8.19 & 4.13 & 5.64 & 2.33 & 2.50 & 2.16 & 3.54 & 6.87 \\
\hline Unemp Rate & 1.58 & 1.08 & 1.56 & 0.51 & 0.75 & 0.32 & 0.69 & 1.63 \\
\hline Average & 3.86 & 2.36 & 3.18 & 1.12 & 1.58 & 0.97 & 1.78 & 3.55 \\
\hline $\begin{array}{l}\text { Financial } \\
\text { Indicator }\end{array}$ & \multicolumn{8}{|c|}{ Average Relative Root MSE } \\
\hline Fed Funds & 0.84 & 1.02 & 0.84 & 1.36 & 1.25 & 1.06 & 1.12 & 1.15 \\
\hline Term Spread & 0.75 & 0.87 & 0.90 & 1.98 & 1.26 & 1.40 & 1.09 & 1.05 \\
\hline Short-term Credit Spread & 0.71 & 0.78 & 0.80 & 1.43 & 1.33 & 0.90 & 1.40 & 0.89 \\
\hline Real M2 & 0.47 & 0.95 & 0.89 & 1.63 & 1.38 & 1.19 & 1.43 & 1.14 \\
\hline SP500 & 0.76 & 1.14 & 0.89 & 1.73 & 1.00 & 1.04 & 0.87 & 0.89 \\
\hline Average & 0.71 & 0.95 & 0.86 & 1.63 & 1.24 & 1.12 & 1.18 & 1.02 \\
\hline
\end{tabular}

Notes: The top panels of the tables show the root mean square forecast errors (RMSE) for the AR models over the indicated sample periods for the real activity variable listed in the first column of the table. The bottom panels shows the corresponding RMSE of the forecasts based on the financial indicators relative to the AR forecasts. The four entries for each financial indicator correspond to the four real activity variables (GDP, IP, Employment, Unemployment Rate). The last rows the table shows the average relative RMSE across the real activity and financial indicators. 
Table 3.3: Average Relative RMSE for Various FCI forecasting models

(a) $h=2$

\begin{tabular}{|c|c|c|c|c|c|c|c|c|}
\hline FCl & $\begin{array}{l}1970 . I- \\
1974 . I V\end{array}$ & $\begin{array}{l}1975 . I- \\
1979 . I V\end{array}$ & $\begin{array}{l}\text { 1980.I - } \\
\text { 1984. IV }\end{array}$ & $\begin{array}{l}\text { 1985.I - } \\
\text { 1989. IV }\end{array}$ & $\begin{array}{l}\text { 1990.I - } \\
\text { 1994. IV }\end{array}$ & $\begin{array}{l}\text { 1995.I - } \\
\text { 1999. IV }\end{array}$ & $\begin{array}{l}\text { 2000.I - } \\
\text { 2004. IV }\end{array}$ & $\begin{array}{l}2005.1 \text { - } \\
\text { EOS }\end{array}$ \\
\hline BLOOMBERG & & & & & & & 0.94 & 0.92 \\
\hline CITI & & & & & & 0.93 & 0.78 & 0.88 \\
\hline$D B(P C)$ & & & & & & & 0.91 & 0.91 \\
\hline$D B(F C I)$ & & & & & & & 0.90 & 0.87 \\
\hline GS & & & & & 1.26 & 1.02 & 0.84 & 0.94 \\
\hline KCFSI & & & & & & & 0.95 & 1.00 \\
\hline$M A$ & & & & & & 1.17 & 0.96 & 0.95 \\
\hline$O E C D$ & & & & & & & & 1.11 \\
\hline Averago all FClc & & & & & & 101 & 200 & ror \\
\hline $\begin{array}{l}\text { Average all FCls } \\
\text { Average from } \\
\text { Table } 3.2\end{array}$ & 0.81 & 0.92 & 0.92 & 1.65 & $\begin{array}{l}1.26 \\
1.19\end{array}$ & $\begin{array}{l}1.04 \\
1.11\end{array}$ & $\begin{array}{l}0.90 \\
1.17\end{array}$ & $\begin{array}{l}0.95 \\
1.02\end{array}$ \\
\hline
\end{tabular}

(b) $h=4$

\begin{tabular}{|c|c|c|c|c|c|c|c|c|}
\hline $\mathbf{F C l}$ & $\begin{array}{l}1970 . I- \\
1974 . I V\end{array}$ & $\begin{array}{l}\text { 1975.I - } \\
\text { 1979.IV }\end{array}$ & $\begin{array}{l}\text { 1980.I - } \\
\text { 1984. IV }\end{array}$ & $\begin{array}{l}\text { 1985.I - } \\
\text { 1989. IV }\end{array}$ & $\begin{array}{l}\text { 1990.I - } \\
\text { 1994. IV }\end{array}$ & $\begin{array}{l}\text { 1995.I - } \\
\text { 1999. IV }\end{array}$ & $\begin{array}{l}\text { 2000.I - } \\
\text { 2004. IV }\end{array}$ & $\begin{array}{l}2005 . I- \\
\text { EOS }\end{array}$ \\
\hline BLOOMBERG & & & & & & & 1.41 & 0.80 \\
\hline CITI & & & & & & 1.02 & 0.75 & 0.83 \\
\hline$D B(P C)$ & & & & & & & 1.15 & 0.78 \\
\hline$D B(F C l)$ & & & & & & & 1.18 & 0.78 \\
\hline GS & & & & & 1.28 & 1.03 & 0.81 & 0.91 \\
\hline KCFSI & & & & & & & 0.81 & 0.84 \\
\hline$M A$ & & & & & & 1.29 & 0.92 & 0.83 \\
\hline$O E C D$ & & & & & & & & 0.90 \\
\hline Average all FCls & & & & & 1.28 & 1.12 & 1.00 & 0.83 \\
\hline $\begin{array}{l}\text { Average from } \\
\text { Table } 3.2\end{array}$ & 0.71 & 0.95 & 0.86 & 1.63 & 1.24 & 1.12 & 1.18 & 1.02 \\
\hline
\end{tabular}

Notes: GS refers to the Goldman Sachs FCI in first difference. DB (PC) and DB (FCI) refer to the Deustche Bank principal component and FCI. See Table 3.2 for additional notes. 
Table 4.1: Financial Indicators

\begin{tabular}{|c|c|c|c|c|c|c|c|c|c|c|c|c|}
\hline & Description & NU & $\mathbf{T}$ & Source & Start & End & \multicolumn{5}{|c|}{$R^{2}-$ Number of Factors } & $\Lambda_{1}$ \\
\hline & Interest Rates & & & & & & 0 & 1 & 2 & 3 & 4 & \\
\hline 1 & 10-Year Treasury Note Yield at Constant Maturity & & 2 & Federal Reserve Board & 1970:2 & 2009:4 & 0.15 & 0.32 & 0.40 & 0.43 & 0.46 & -0.36 \\
\hline 2 & FedFunds/3monthTBill Spread & $\mathrm{X}$ & 1 & Federal Reserve Board & $1970: 2$ & 2009:4 & 0.42 & 0.62 & 0.62 & 0.68 & 0.68 & -0.43 \\
\hline 3 & 2YrT-note/3monthTbill Spread & $\mathrm{X}$ & 1 & Federal Reserve Board & 1976:3 & 2009:4 & 0.03 & 0.27 & 0.34 & 0.48 & 0.76 & 0.25 \\
\hline 4 & 10YrT-note/3monthTbill Spread & $\mathrm{X}$ & 1 & Federal Reserve Board & 1970:2 & 2009:4 & 0.21 & 0.39 & 0.57 & 0.75 & 0.77 & 0.38 \\
\hline 5 & Baa/10yr T-note Spread & & 1 & Federal Reserve Board & 1970:2 & 2009:4 & 0.39 & 0.44 & 0.82 & 0.82 & 0.83 & -0.06 \\
\hline 6 & High Yield / Baa Spread & & 1 & $\begin{array}{l}\text { Merrill Lynch/Federal Reserve } \\
\text { Board }\end{array}$ & 1997:1 & 2009:4 & 0.73 & 0.92 & 0.95 & 0.95 & 0.95 & -0.17 \\
\hline 7 & $\begin{array}{l}\text { Auto finance company loan rate, new Car/Two-yr } \\
\text { Treasury Spread }\end{array}$ & $\mathrm{X}$ & 1 & Federal Reserve Board & 1976:3 & 2009:4 & 0.06 & 0.40 & 0.41 & 0.71 & 0.73 & 0.46 \\
\hline 8 & 30-yr Conventional mortgage/ 10yrTBond Spread & & 1 & Federal Reserve Board & 1971:2 & 2009:4 & 0.23 & 0.34 & 0.42 & 0.54 & 0.66 & -0.23 \\
\hline 9 & Jumbo/30yr Conventional Spread & $\mathrm{X}$ & 1 & Deutsche Bank & 1998:3 & 2009:4 & 0.60 & 0.94 & 0.94 & 0.96 & 0.96 & -0.44 \\
\hline 10 & TED Spread (Using Constant Maturity T-bill) & & 1 & Federal Reserve Board & 1981:4 & 2009:4 & 0.32 & 0.72 & 0.76 & 0.75 & 0.84 & -0.61 \\
\hline 11 & 3-month LIBOR/OIS & & 1 & $\begin{array}{l}\text { Bloomberg/Federal Reserve } \\
\text { Board }\end{array}$ & $2002: 1$ & 2009:4 & 0.71 & 0.97 & 0.97 & 0.97 & 0.98 & -0.35 \\
\hline 12 & $\begin{array}{l}\text { Bank rate on new Car Loans, 48-month/Two-year } \\
\text { Treasury Spread }\end{array}$ & $\mathrm{X}$ & 1 & $\begin{array}{l}\text { Wall Street Journal/Federal } \\
\text { Reserve Board }\end{array}$ & 1976:3 & 2009:4 & 0.37 & 0.59 & 0.81 & 0.80 & 0.87 & 0.37 \\
\hline 13 & $\begin{array}{l}\text { Bank rate on Personal Loans, 24-month/Two-year } \\
\text { Treasury Spread }\end{array}$ & $\mathrm{X}$ & 1 & Federal Reserve Board & 1976:3 & 2009:4 & 0.72 & 0.81 & 0.85 & 0.84 & 0.93 & 0.22 \\
\hline 14 & Citigroup Bond Yields:Credit \{Corp\} Spread/Finance & $\mathrm{X}$ & 1 & Citi & $1980: 1$ & 2009:4 & 0.28 & 0.73 & 0.75 & 0.73 & 0.78 & -0.65 \\
\hline 15 & Banks CDS Spread & $X$ & 1 & Deutsche Bank & 2004:4 & 2009:4 & 0.88 & 0.99 & 0.99 & 0.99 & 0.99 & -0.10 \\
\hline & Prices & & & & & & & & & & & \\
\hline 16 & $\begin{array}{l}\text { Real Broad Trade-Weighted Exchange Value of the } \\
\text { US } \$\end{array}$ & & 5 & Federal Reserve Board & 1973:2 & 2009:4 & 0.02 & 0.19 & 0.20 & 0.21 & 0.29 & -0.24 \\
\hline 17 & Wilshire 5000 & & 5 & Wilshire Associates & 1971:2 & 2009:4 & 0.09 & 0.36 & 0.46 & 0.46 & 0.49 & 0.48 \\
\hline 18 & Financial Market Cap (percent of S\&P 500) & $\mathrm{X}$ & 5 & Standard and Poor's & $1976: 4$ & 2009:4 & 0.04 & 0.34 & 0.41 & 0.41 & 0.40 & 0.38 \\
\hline 19 & Loan Performance National House Price Index (SA) & $\mathrm{X}$ & 5 & FirstAmerican Core Logic & 1976:2 & 2009:4 & 0.31 & 0.57 & 0.60 & 0.66 & 0.69 & 0.43 \\
\hline 20 & Price of Oil Relative to 2Year MA (PPI Crude Oil) & $\mathrm{X}$ & 4 & Wall Street Journal & 1970:2 & 2009:4 & 0.13 & 0.18 & 0.28 & 0.30 & 0.26 & -0.18 \\
\hline & Quantities & & & & & & & & & & & \\
\hline 21 & Bank Credit: All Commercial Banks (SA) & $\mathrm{X}$ & 5 & Federal Reserve Board & 1970:2 & 2009:4 & 0.28 & 0.32 & 0.33 & 0.53 & 0.59 & 0.02 \\
\hline 22 & Commercial Paper Outstanding:All Issuers (SA) & $\mathrm{X}$ & 5 & Federal Reserve Board & 1970:2 & 2009:4 & 0.32 & 0.39 & 0.52 & 0.58 & 0.71 & -0.17 \\
\hline 23 & $\begin{array}{l}\text { Commercial Paper Issuance (Relative to 24Month } \\
\text { MA) }\end{array}$ & & 1 & Federal Reserve Board & $2002: 1$ & 2009:4 & 0.79 & 0.97 & 0.98 & 0.98 & 0.99 & -0.14 \\
\hline 24 & ABS Issuance (Relative to 24Month MA) & & 1 & Bloomberg & 1997:1 & 2009:4 & 0.32 & 0.92 & 0.92 & 0.93 & 0.96 & 0.68 \\
\hline 25 & $\begin{array}{l}\text { CMBS Issuance (Alert Database) (Relative to } \\
\text { 24Month MA) }\end{array}$ & & 1 & Deutsche Bank & 1992:1 & 2009:4 & 0.29 & 0.79 & 0.79 & 0.82 & 0.90 & 0.51 \\
\hline 26 & Money Stock:MZM \{Zero Maturity\} (SA) & & 5 & $\begin{array}{l}\text { Federal Reserve Bank of St. } \\
\text { Louis }\end{array}$ & 1974:2 & 2009:4 & 0.13 & 0.30 & 0.49 & 0.55 & 0.52 & 0.21 \\
\hline 27 & $\begin{array}{l}\text { State \& local Government:Liability:Credit Market } \\
\text { Instruments (SA) }\end{array}$ & $\mathrm{X}$ & 5 & Federal Reserve Board & 1970:2 & 2009:4 & 0.04 & 0.13 & 0.22 & 0.54 & 0.55 & 0.21 \\
\hline 28 & $\begin{array}{l}\text { Nonfederal Sectors:Liability:Credit Market Debt } \\
\text { Outstanding (SA) }\end{array}$ & $\mathrm{X}$ & 5 & Federal Reserve Board & 1970:2 & 2009:4 & 0.47 & 0.50 & 0.50 & 0.88 & 0.88 & 0.06 \\
\hline
\end{tabular}




\begin{tabular}{|c|c|c|c|c|c|c|c|c|c|c|c|c|}
\hline 29 & Private Nonfinancial Debt, SA & $\mathrm{X}$ & 5 & Federal Reserve Board & $1970: 2$ & $2009: 4$ & 0.52 & 0.54 & 0.55 & 0.85 & 0.85 & 0.02 \\
\hline 30 & Total Finance:Liabilities:Security RPs (NSA) & $\mathrm{X}$ & 5 & Federal Reserve Board & 1974:2 & $2009: 4$ & 0.07 & 0.31 & 0.42 & 0.43 & 0.50 & 0.36 \\
\hline 31 & ABS Issuers:Assets; Consumer Credit (NSA) & $\mathrm{X}$ & 5 & Federal Reserve Board & 1992:2 & $2009: 3$ & 0.16 & 0.67 & 0.73 & 0.75 & 0.85 & 0.30 \\
\hline 32 & $\begin{array}{l}\text { ABS Issuers:Asset; Mortgages on 1-4 Family } \\
\text { Structures (NSA) }\end{array}$ & $\mathrm{X}$ & 5 & Federal Reserve Board & 1988:2 & $2009: 4$ & 0.22 & 0.73 & 0.76 & 0.76 & 0.88 & 0.62 \\
\hline 33 & ABS Issuers:Asset; Commercial Mortgages (NSA) & $\mathrm{X}$ & 5 & Federal Reserve Board & 1993:2 & 2009:4 & 0.28 & 0.75 & 0.75 & 0.81 & 0.92 & 0.34 \\
\hline 34 & $\begin{array}{l}\text { Total Non-monrtgage ABS Issuance (NSA) Relative } \\
\text { to } 8 \mathrm{Q} \text { MA) }\end{array}$ & & 1 & Deutsche Bank & 1994:1 & 2009:4 & 0.28 & 0.90 & 0.90 & 0.89 & 0.94 & 0.78 \\
\hline \multirow[t]{2}{*}{35} & Broker Dealer Leverage & $\mathrm{X}$ & 5 & Federal Reserve Board & 1970:2 & $2009: 4$ & 0.03 & 0.14 & 0.20 & 0.19 & 0.23 & 0.24 \\
\hline & Surveys & & & & & & & & & & & \\
\hline 36 & $\begin{array}{l}\text { NFIB:\%Reporting that Credit Was Harder to Get Last } \\
\text { Time, Net (SA) }\end{array}$ & $\mathrm{X}$ & 1 & $\begin{array}{l}\text { National Federation of } \\
\text { Independent Business }\end{array}$ & 1986:1 & 2009:4 & 0.42 & 0.69 & 0.69 & 0.84 & 0.84 & -0.22 \\
\hline 37 & $\begin{array}{l}\text { Michigan Survey:Interest Rates/Credit Reason } \\
\text { Good/Bad Conditions for Buying Large HH Goods } \\
\text { Spread }\end{array}$ & $\mathrm{X}$ & 1 & University of Michigan & 1978:1 & $2009: 4$ & 0.68 & 0.81 & 0.82 & 0.83 & 0.91 & -0.29 \\
\hline 38 & $\begin{array}{l}\text { Michigan Survey:Interest Rates/Credit Reason for } \\
\text { Good/Bad Conditions for Buying Houses Spread }\end{array}$ & $\mathrm{X}$ & 1 & University of Michigan & 1980:2 & $2009: 4$ & 0.70 & 0.86 & 0.87 & 0.86 & 0.93 & -0.35 \\
\hline 39 & $\begin{array}{l}\text { Michigan Survey:Interest Rates/Credit Reason for } \\
\text { Good Less Bad Conditions for Buying Autos Spread }\end{array}$ & $\mathrm{X}$ & 1 & University of Michigan & 1978:1 & 2009:4 & 0.56 & 0.75 & 0.80 & 0.82 & 0.89 & -0.36 \\
\hline 40 & $\begin{array}{l}\text { FRB Sr. Of. Banks Tightening C\&I Loans to Large } \\
\text { Firms (\%) }\end{array}$ & $\mathrm{X}$ & 1 & Federal Reserve Board & 1990:2 & $2009: 4$ & 0.45 & 0.81 & 0.83 & 0.83 & 0.88 & -0.45 \\
\hline 41 & $\begin{array}{l}\text { FRB Sr. Of.:Banks Tightening C\&I Loans to Small } \\
\text { Firms (\%) }\end{array}$ & $\mathrm{X}$ & 1 & Federal Reserve Board & 1990:2 & 2009:4 & 0.54 & 0.86 & 0.87 & 0.87 & 0.91 & -0.48 \\
\hline \multirow[t]{2}{*}{42} & $\begin{array}{l}\text { FRB Sr. Of.:Banks Willingness to Lend to Consumers } \\
(\%)\end{array}$ & $\mathrm{X}$ & 1 & Federal Reserve Board & 1970:2 & 2009:4 & 0.24 & 0.59 & 0.60 & 0.63 & 0.66 & 0.58 \\
\hline & $2^{\text {nd }}$ Moments & & & & & & & & & & & \\
\hline 43 & Correlation of Returns on Equities and Treasuries & & 1 & $\begin{array}{l}\text { Authors' calculations based } \\
\text { on Standard and Poor's } \\
\text { and US Treasury data }\end{array}$ & 1976:3 & $2009: 4$ & 0.18 & 0.38 & 0.47 & 0.51 & 0.69 & 0.23 \\
\hline 44 & Idiosyncratic Bank Stock Volatility & & 1 & Goldman Sachs & 1973:1 & 2009:4 & 0.20 & 0.52 & 0.71 & 0.72 & 0.77 & -0.53 \\
\hline \multirow[t]{2}{*}{45} & Monthly Average VIX & & 1 & Chicago Options Exchange & $1986: 1$ & 2009:4 & 0.24 & 0.73 & 0.81 & 0.8 & 0.82 & -0.64 \\
\hline & Average $R^{2}$ & & & & & & 0.29 & 0.41 & 0.49 & 0.57 & 0.65 & \\
\hline
\end{tabular}

Notes: In the column labeled $N U$, an " $\mathrm{X}$ " denotes variable was not used in any of the alternative FCIs we have surveyed. The column labeled $T$ shows the transformation ( $1=$ level, $2=$ first difference, $4=$ logarithm, $5=$ first difference of logarithm). The start and end dates indicate the periods the series was used in to estimate the factors. The five columns labeled $R^{2}$ show the $R^{2}$ for model including $\mathrm{A}(\mathrm{L}) Y$, and then sequentially adding 0,1 , and 4 factors. The column labeled $\Lambda_{1}$ shows the estimated value of $\Lambda$ for the single factor model. 
Figure 4.1: Number of Financial Indicators by Date

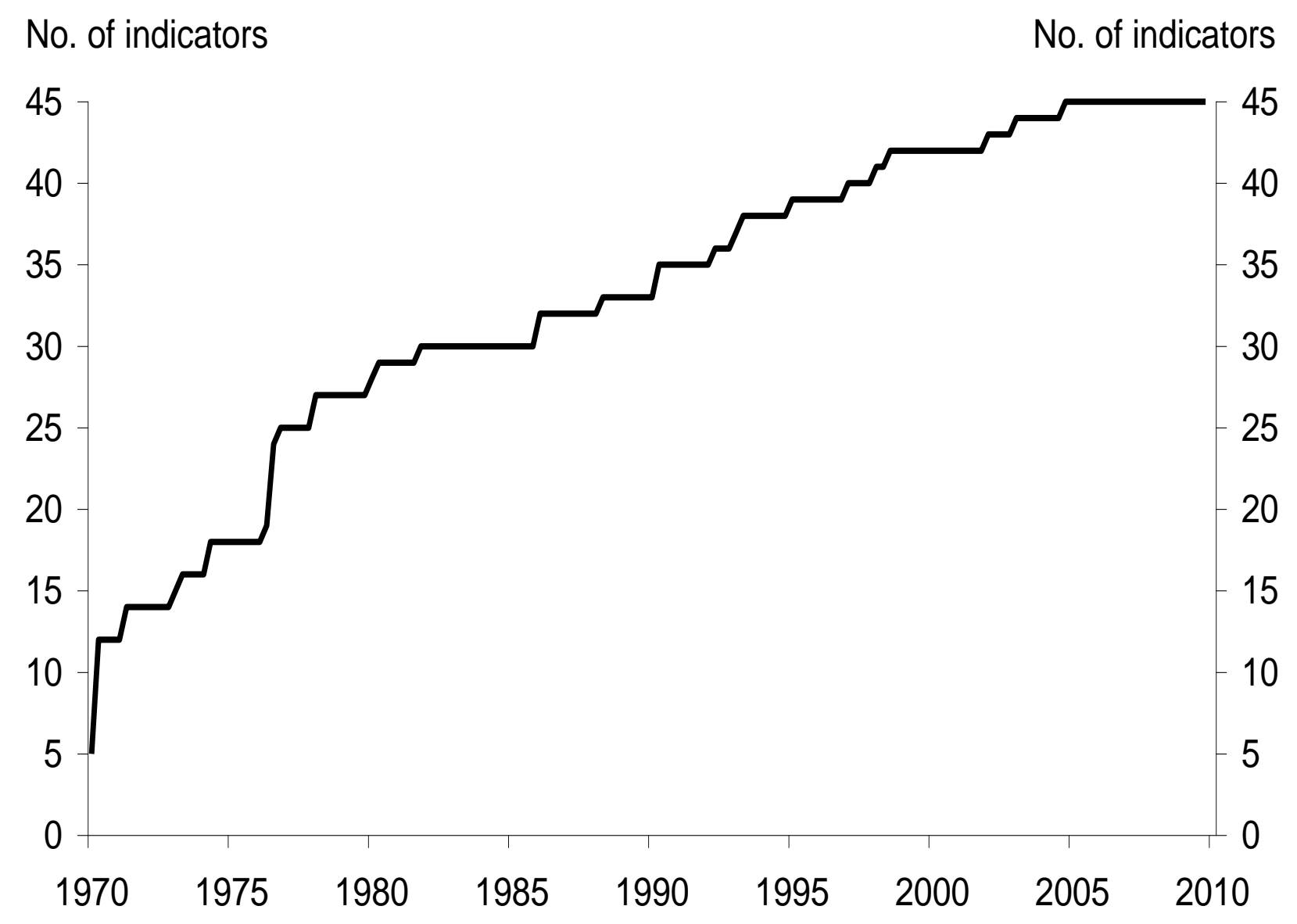




\title{
Figure 4.2: Ranking of variables by their lambdas in single factor model
}

\author{
Financial indicator( lambda absolute value) * Absolute value of lambda
}

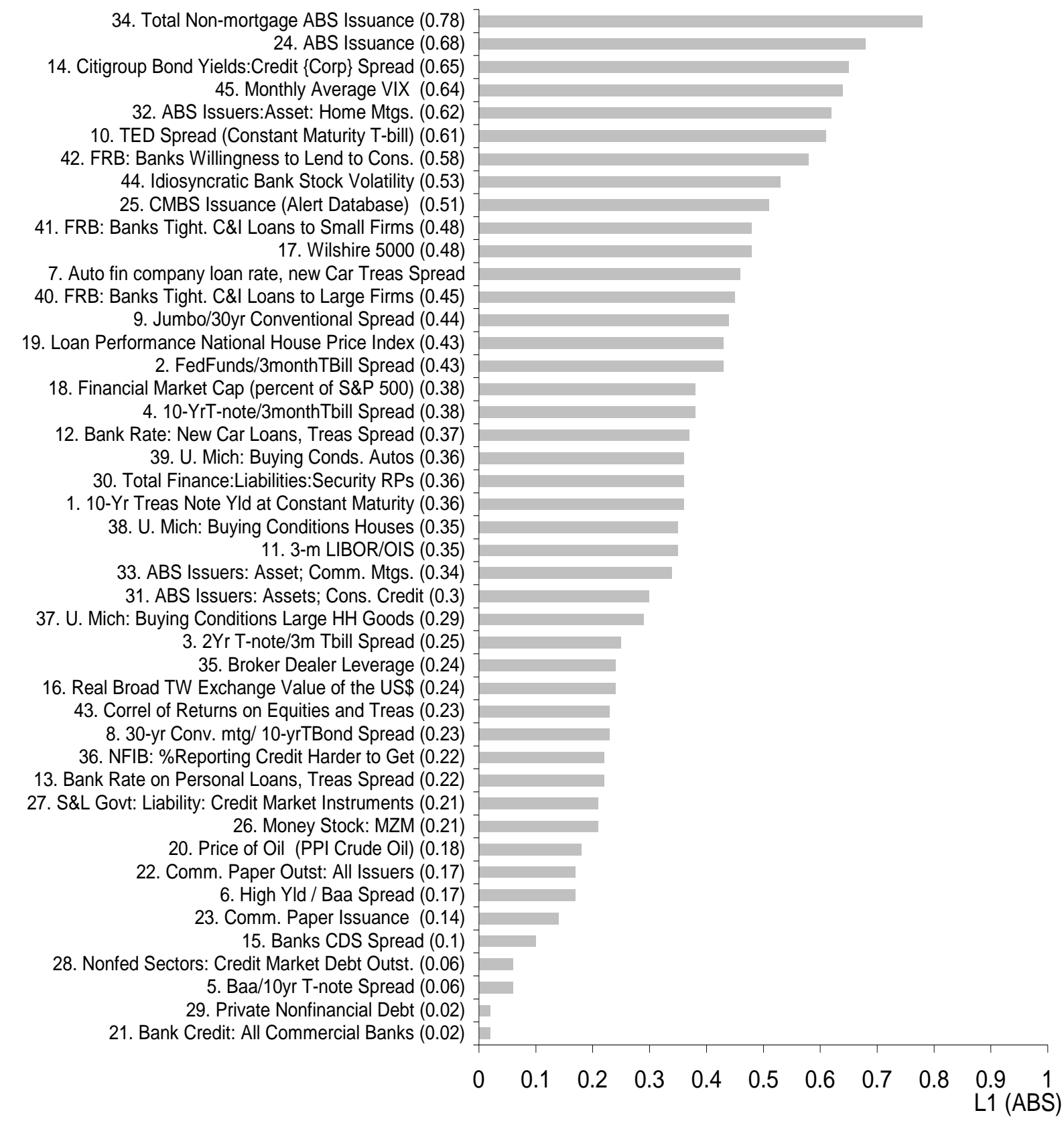

*Numbers preceding variable name correspond to line numbers in table 4.1. 


\section{Figure 4.3: Ranking of variables by their lambdas in single factor model}

Financial indicator (lambda value) *

34. Total Non-mortgage ABS Issuance (0.78)

24. ABS Issuance (0.68)

32. ABS Issuers:Asset: Home Mtgs. (0.62)

42. FRB: Banks Willingness to Lend to Cons. (0.58)

25. CMBS Issuance (Alert Database) (0.51)

17. Wilshire $5000(0.48)$

7. Auto fin company loan rate, new Car Treas Spread (0.46)

19. Loan Performance National House Price Index (0.43)

18. Financial Market Cap (percent of S\&P 500) (0.38)

4. 10-YrT-note/3monthTbill Spread (0.38)

12. Bank Rate: New Car Loans, Treas Spread (0.37)

30. Total Finance:Liabilities:Security RPs $(0.36)$

33. ABS Issuers: Asset; Comm. Mtgs. (0.34)

31. ABS Issuers: Assets; Cons. Credit (0.3)

3. 2 Yr T-note/3m Tbill Spread (0.25)

35. Broker Dealer Leverage (0.24)

43. Correl of Returns on Equities and Treas (0.23)

13. Bank Rate on Personal Loans, Treas Spread (0.22)

27. S\&L Govt: Liability: Credit Market Instruments (0.21)

26. Money Stock: MZM (0.21)

28. Nonfed Sectors: Credit Market Debt Outst. (0.06)

29. Private Nonfinancial Debt (0.02)

21. Bank Credit: All Commercial Banks (0.02)

5. Baa/10yr T-note Spread $(-0.06)$

15. Banks CDS Spread $(-0.1)$

23. Comm. Paper Issuance $(-0.14)$

22. Comm. Paper Outst: All Issuers (-0.17)

6. High Yld / Baa Spread (-0.17)

20. Price of Oil (PPI Crude Oil) (-0.18)

36. NFIB: \%Reporting Credit Harder to Get(-0.22)

8. 30-yr Conv. mtg/ 10-yrTBond Spread (-0.23)

16. Real Broad TW Exchange Value of the US\$ $(-0.24)$

37. U. Mich: Buying Conditions Large HH Goods $(-0.29)$

38. U. Mich: Buying Conditions Houses (-0.35)

11. 3-m LIBOR/OIS (-0.35)

39. U. Mich: Buying Conds. Autos (-0.36)

1. $10-$ Yr Treas Note Yld at Constant Maturity $(-0.36)$

2. FedFunds/3monthTBill Spread $(-0.43)$

9. Jumbo/30yr Conventional Spread $(-0.44)$

40. FRB: Banks Tight. C\&I Loans to Large Firms $(-0.45)$

41. FRB: Banks Tight. C\&I Loans to Small Firms $(-0.48)$

44. Idiosyncratic Bank Stock Volatility $(-0.53)$

10. TED Spread (Constant Maturity T-bill) $(-0.61)$

45. Monthly Average VIX (-0.64)

14. Citigroup Bond Yields:Credit \{Corp\} Spread (-0.65) lambda value

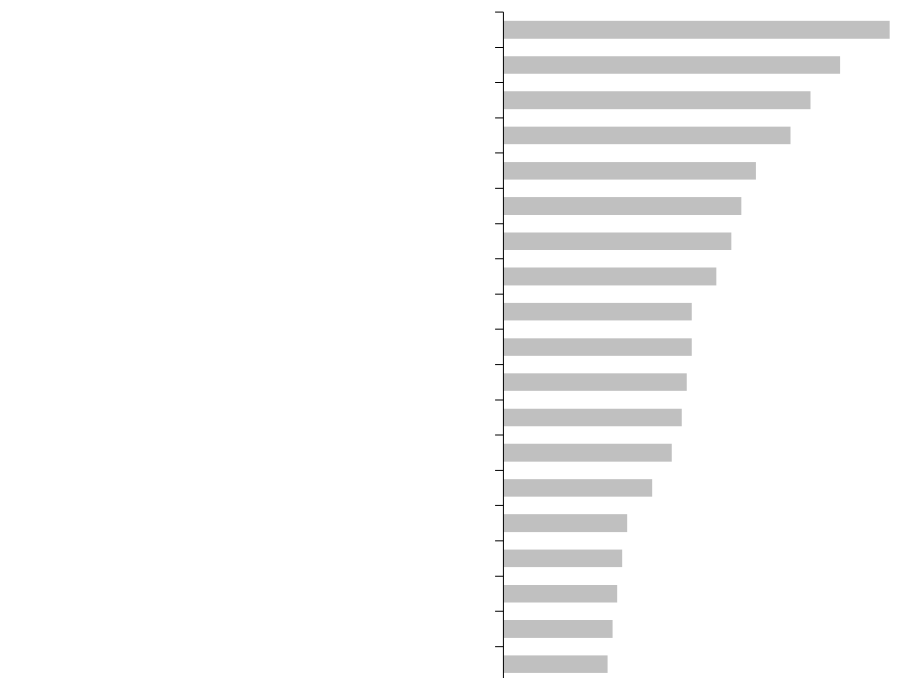

$\begin{array}{lllllllll}-1 & -0.75 & -0.5 & -0.25 & 0 & 0.25 & 0.5 & 0.75 & L_{1}^{1}\end{array}$

*Numbers preceding variable name correspond to line numbers in table 4.1. 
Figure 5.1: New FCI: First Principal Component of 45 Financial Indicators

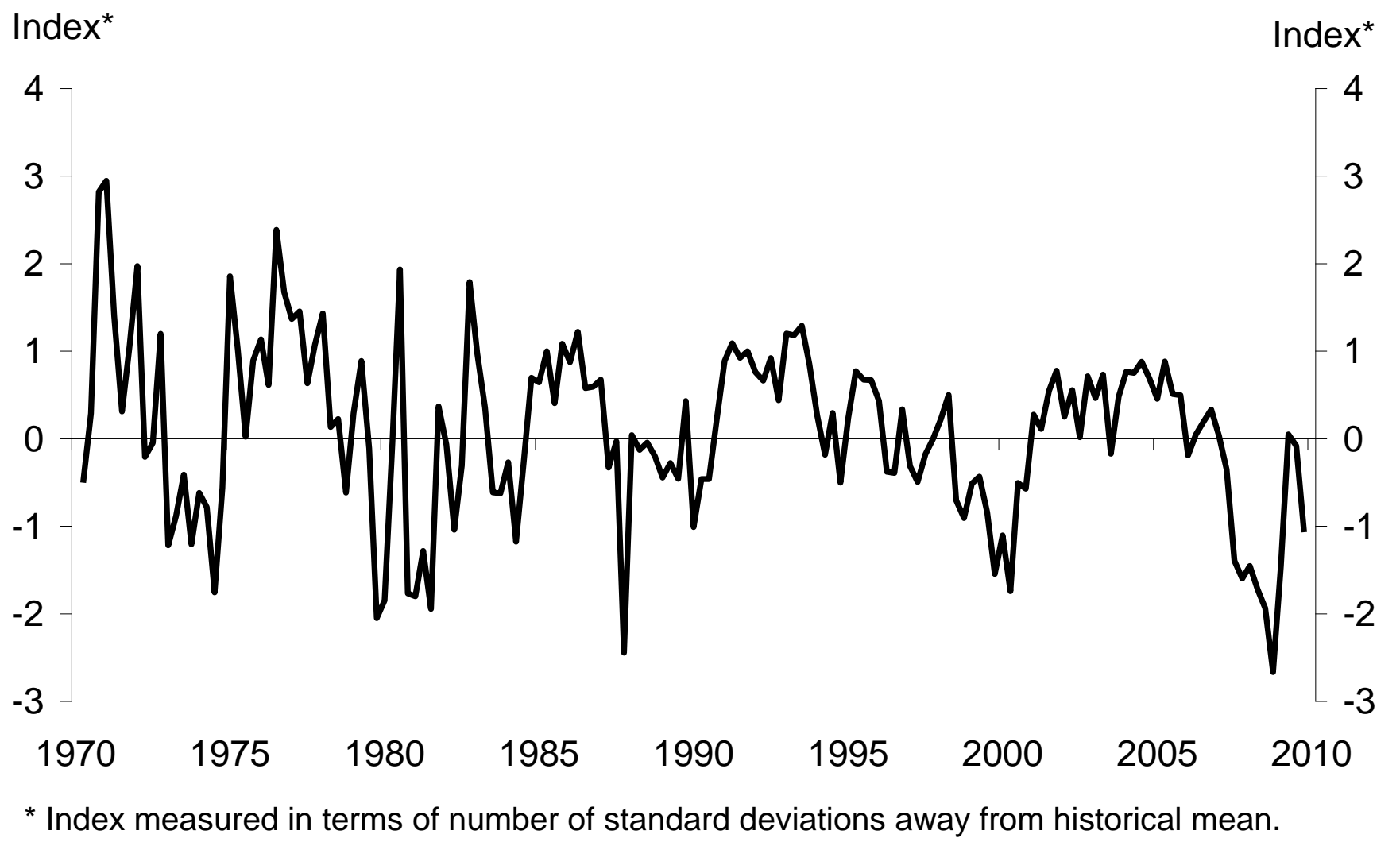


Table 5.1: Relative RMSE for Forecasting Models Using Financial Indicator Factors

(a) $h=2$

\begin{tabular}{|c|c|c|c|c|c|c|c|c|}
\hline $\mathrm{FCl}$ & $\begin{array}{l}1970 . I- \\
1974 . I V \\
\end{array}$ & $\begin{array}{l}1975 . I- \\
1979 . I V\end{array}$ & $\begin{array}{l}1980 . I- \\
\text { 1984. IV }\end{array}$ & $\begin{array}{l}1985 . I- \\
\text { 1989. IV }\end{array}$ & $\begin{array}{l}1990 . I- \\
\text { 1994. IV }\end{array}$ & $\begin{array}{l}\text { 1995.I - } \\
\text { 1999. IV }\end{array}$ & $\begin{array}{l}\text { 2000.I - } \\
\text { 2004. IV }\end{array}$ & $\begin{array}{l}2005 . I- \\
\text { EOS }\end{array}$ \\
\hline $1 P C$ & & & 0.87 & 1.55 & 0.88 & 1.60 & 0.93 & 0.66 \\
\hline $2 P C s$ & & & 0.82 & 1.89 & 1.04 & 1.87 & 1.01 & 0.69 \\
\hline $3 P C s$ & & & 0.90 & 1.64 & 1.02 & 2.03 & 0.89 & 0.73 \\
\hline Average & & & 0.86 & 1.69 & 0.98 & 1.83 & 0.94 & 0.69 \\
\hline $\begin{array}{l}\text { AR Model RMSE } \\
\text { Avg (Tab 3.2) }\end{array}$ & 3.86 & 2.77 & 3.38 & 1.03 & 1.69 & 1.02 & 1.64 & 3.05 \\
\hline SP500 (Tab. 3.2) & 0.74 & 1.06 & 0.88 & 1.88 & 1.00 & 1.18 & 0.87 & 0.84 \\
\hline KCFSI (Tab. 3.3) & & & & & & & 0.95 & 1.00 \\
\hline Avg (Tab. 3.2) & 0.81 & 0.91 & 0.92 & 1.65 & 1.19 & 1.12 & 1.17 & 1.02 \\
\hline Avg (Tab. 3.3) & & & & & 1.26 & 1.04 & 0.90 & 0.95 \\
\hline
\end{tabular}

(b) $h=4$

\begin{tabular}{|l|c|c|c|c|c|c|c|c|}
\hline FCI & $\begin{array}{l}1970 . I- \\
1974 . I V\end{array}$ & $\begin{array}{l}1975 . I- \\
1979 . I V\end{array}$ & $\begin{array}{l}1980 . I- \\
1984 . ~ I V\end{array}$ & $\begin{array}{l}1985 . I- \\
1989 . I V\end{array}$ & $\begin{array}{l}1990 . I- \\
1994 . I V\end{array}$ & $\begin{array}{l}1995 . I- \\
1999 . I V\end{array}$ & $\begin{array}{l}2000 . I- \\
2004 . ~ I V\end{array}$ & $\begin{array}{l}2005 . I- \\
\text { EOS }\end{array}$ \\
\hline 1 PC & & & 1.04 & 1.46 & 0.82 & 1.83 & 0.83 & 0.60 \\
\hline 2 PCs & & & 0.93 & 1.61 & 0.99 & 3.01 & 0.93 & 0.63 \\
\hline 3 PCs & & & 0.92 & 1.49 & 1.00 & 3.51 & 0.78 & 0.68 \\
\hline Average & & & 0.96 & 1.52 & 0.94 & 2.78 & 0.85 & 0.63 \\
\hline & & & & & & & & \\
\hline $\begin{array}{l}\text { AR Model RMSE } \\
\text { Avg (Tab 3.2) }\end{array}$ & 3.86 & 2.36 & 3.18 & 1.12 & 1.58 & 0.97 & 1.78 & 3.55 \\
\hline SP500 (Tab. 3.2) & 0.76 & 1.14 & 0.89 & 1.73 & 1.00 & 1.04 & 0.87 & 0.89 \\
\hline KCFSI (Tab. 3.3) & & & & & & & 0.81 & 0.84 \\
\hline Avg (Tab. 3.2) & 0.71 & 0.95 & 0.86 & 1.63 & 1.24 & 1.12 & 1.18 & 1.02 \\
\hline Avg (Tab. 3.3) & & & & & 1.28 & 1.12 & 1.00 & 0.83 \\
\hline
\end{tabular}


Figure 5.2: Real GDP Growth: Forecast using Autoregressive and New FCI Models $(\mathrm{h}=2) *$ $\mathrm{Q} / \mathrm{Q} \% \mathrm{AR}$ $\mathrm{Q} / \mathrm{Q} \% \mathrm{AR}$

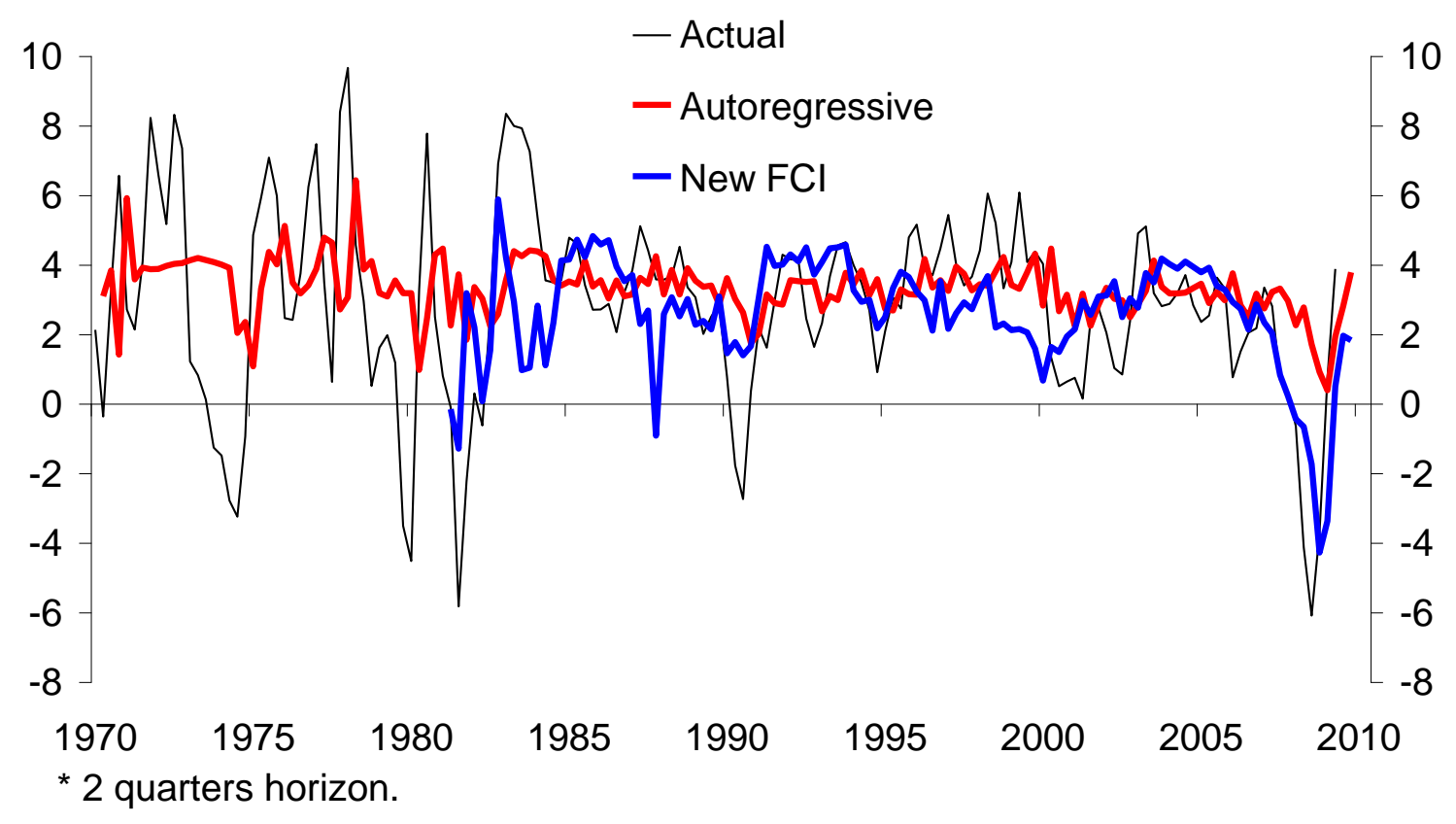

Figure 5.3 a Real GDP Growth: Forecast using SP500 and New FCI $(h=2)^{*}$ $\mathrm{Q} / \mathrm{Q} \% \mathrm{AR}$ $\mathrm{Q} / \mathrm{Q} \% \mathrm{AR}$

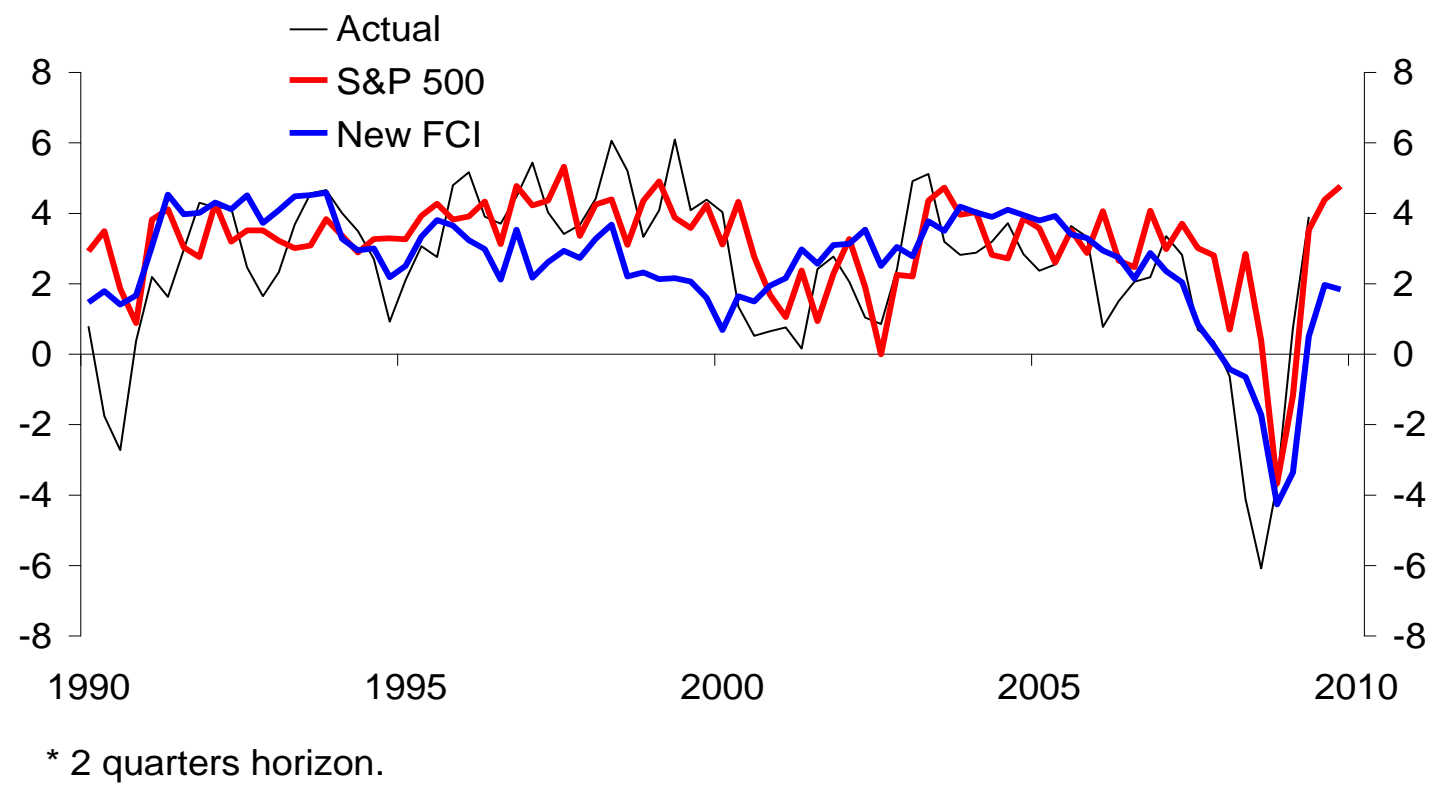


Figure 5.3 b. Real GDP Growth: Forecast using Alternative FCIs $(h=2)^{*}$

$Q / Q \% A R$

$\mathrm{Q} / \mathrm{Q} \% \mathrm{AR}$

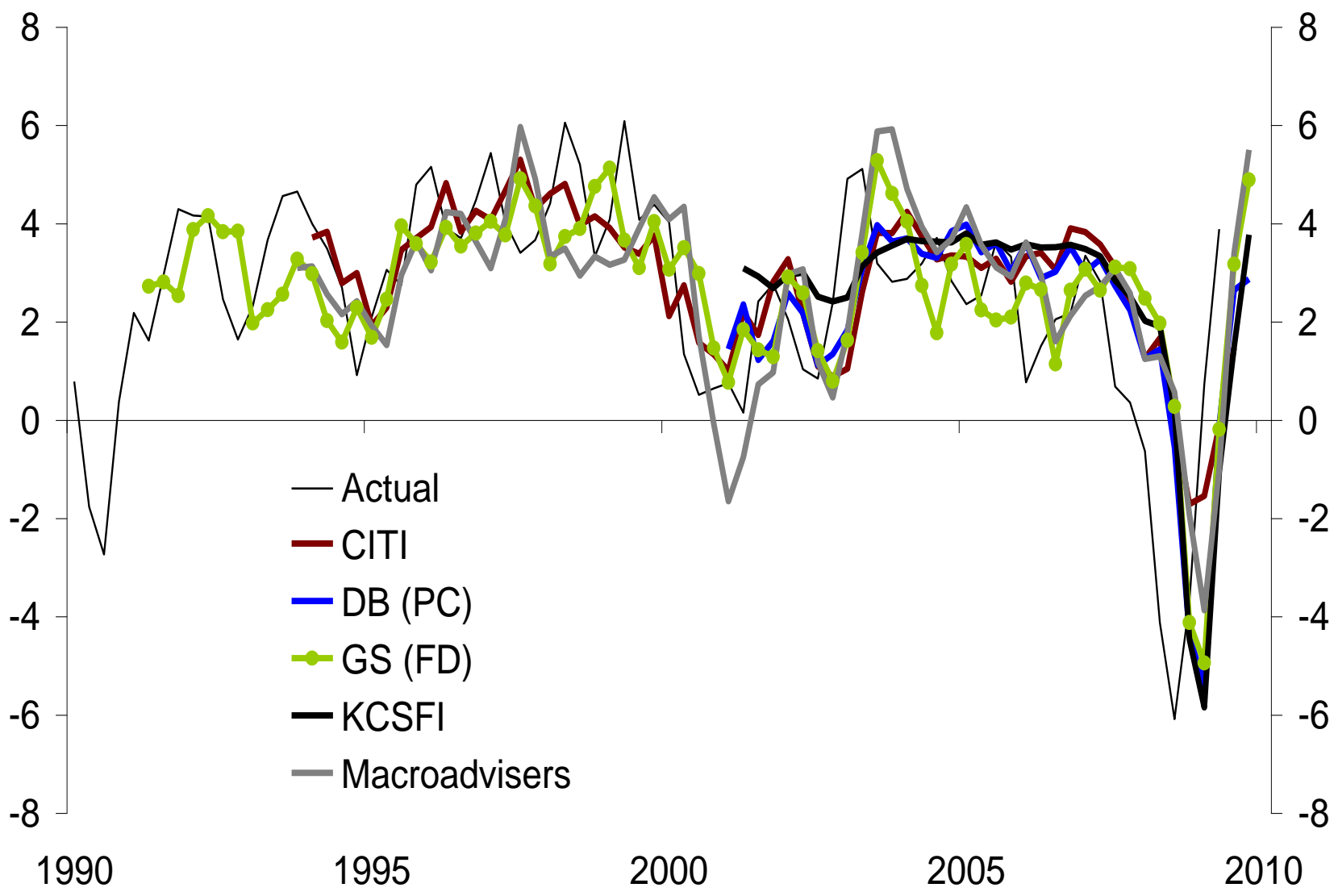


Table 5.2: Relative RMSE for Subsets of Financial Indicators

(a) $h=2$

\begin{tabular}{|c|c|c|c|c|c|c|c|c|}
\hline Subset & $\begin{array}{l}1970 . I- \\
1974 . I V\end{array}$ & $\begin{array}{l}1975 . I- \\
1979 . I V\end{array}$ & $\begin{array}{c}\text { 1980.I - } \\
\text { 1984. IV }\end{array}$ & $\begin{array}{c}\text { 1985.I - } \\
\text { 1989. IV }\end{array}$ & $\begin{array}{c}1990 . I- \\
\text { 1994. IV }\end{array}$ & $\begin{array}{c}1995 . I- \\
\text { 1999. IV }\end{array}$ & $\begin{array}{l}\text { 2000.I - } \\
\text { 2004. IV }\end{array}$ & $\begin{array}{c}2005.1- \\
\text { EOS }\end{array}$ \\
\hline New FCl & & & 0.87 & 1.55 & 0.88 & 1.60 & 0.93 & 0.66 \\
\hline Balanced Panel & & & 0.82 & 1.35 & 0.91 & 2.20 & 0.88 & 0.75 \\
\hline Price & & & & 2.29 & 1.13 & 1.54 & 0.82 & 0.80 \\
\hline Quantity & & & & . & . & . & & 1.08 \\
\hline Surveys & & & & 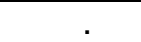 & . & . & 1.17 & 0.91 \\
\hline Liquidity & & & & 1.43 & 0.89 & 1.81 & 0.84 & 0.98 \\
\hline Credit & & & & . & 1.42 & 1.11 & 0.96 & 0.90 \\
\hline $\begin{array}{l}\text { Not purged of } \\
\text { either macro } \\
\text { influence or fed } \\
\text { funds }\end{array}$ & & & 0.73 & 1.38 & 1.08 & 0.97 & 1.10 & 0.86 \\
\hline $\begin{array}{l}\text { Purged of both } \\
\text { macro influence } \\
\text { and fed funds }\end{array}$ & & & 1.01 & 1.58 & 0.95 & 1.30 & 0.94 & 0.74 \\
\hline
\end{tabular}

(b) $h=4$

\begin{tabular}{|c|c|c|c|c|c|c|c|c|}
\hline Subset & $\begin{array}{l}1970 . I- \\
1974 . I V \\
\end{array}$ & $\begin{array}{l}1975 . I- \\
1979 . I V \\
\end{array}$ & $\begin{array}{l}\text { 1980.I - } \\
\text { 1984. IV }\end{array}$ & $\begin{array}{l}\text { 1985.I - } \\
\text { 1989. IV }\end{array}$ & $\begin{array}{l}\text { 1990.I - } \\
\text { 1994. IV }\end{array}$ & $\begin{array}{l}\text { 1995.I - } \\
\text { 1999. IV }\end{array}$ & $\begin{array}{l}\text { 2000.I - } \\
\text { 2004. IV }\end{array}$ & $\begin{array}{c}2005 . I- \\
\text { EOS }\end{array}$ \\
\hline New FCl & & & 1.08 & 1.40 & 0.81 & 1.93 & 0.77 & 0.60 \\
\hline Balanced Panel & & & 0.85 & 1.22 & 0.90 & 3.01 & 0.73 & 0.68 \\
\hline Price & & & & 0.97 & 1.04 & 1.61 & 0.75 & 0.72 \\
\hline Quantity & & & & . & . & . & . & 0.80 \\
\hline Surveys & & & & . & . & . & 1.62 & 0.77 \\
\hline Liquidity & & & & 0.85 & 0.72 & 2.95 & 0.75 & 0.87 \\
\hline Credit & & & & . & 1.50 & 1.19 & 0.92 & 0.89 \\
\hline $\begin{array}{l}\text { Not purged of } \\
\text { either macro } \\
\text { influence or fed } \\
\text { funds }\end{array}$ & & & 0.89 & 1.30 & 1.03 & 0.84 & 1.09 & 0.89 \\
\hline $\begin{array}{l}\text { Purged of both } \\
\text { macro influence } \\
\text { and fed funds }\end{array}$ & & & 1.21 & 1.29 & 0.87 & 1.22 & 0.86 & 0.73 \\
\hline
\end{tabular}


Figure 5.4 Decomposition of FCI

Index*

Index*
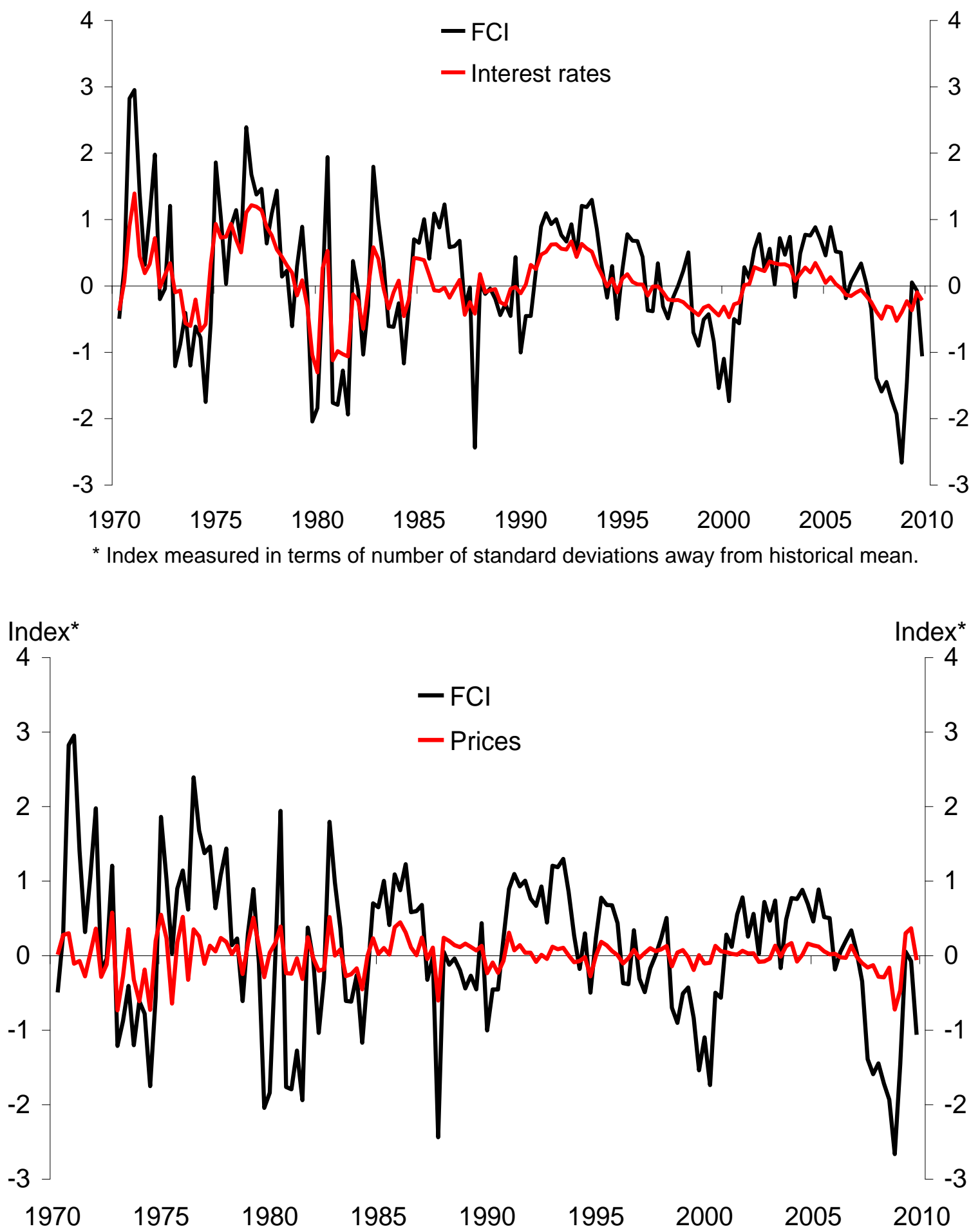

* Index measured in terms of number of standard deviations away from historical mean. 

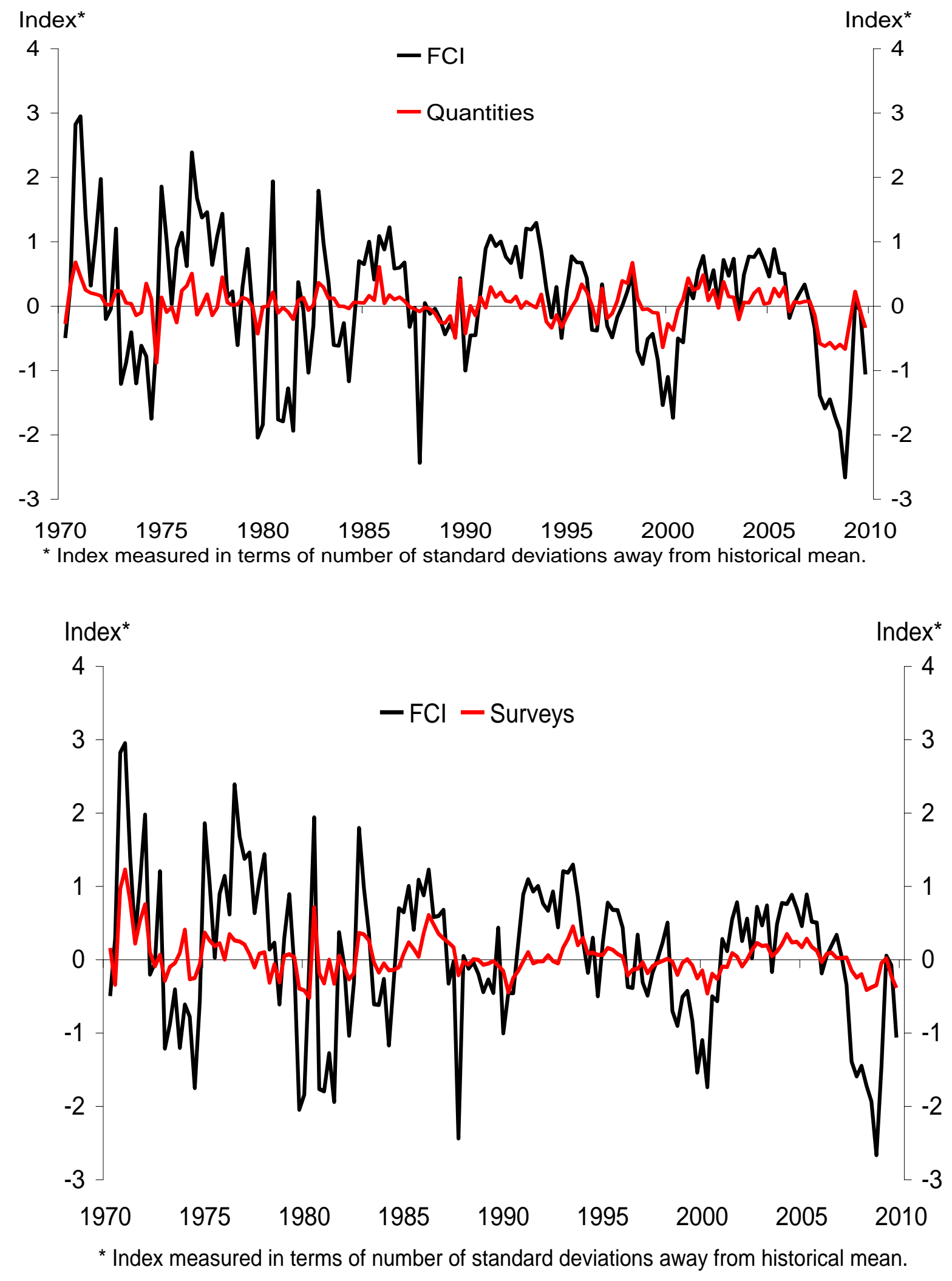


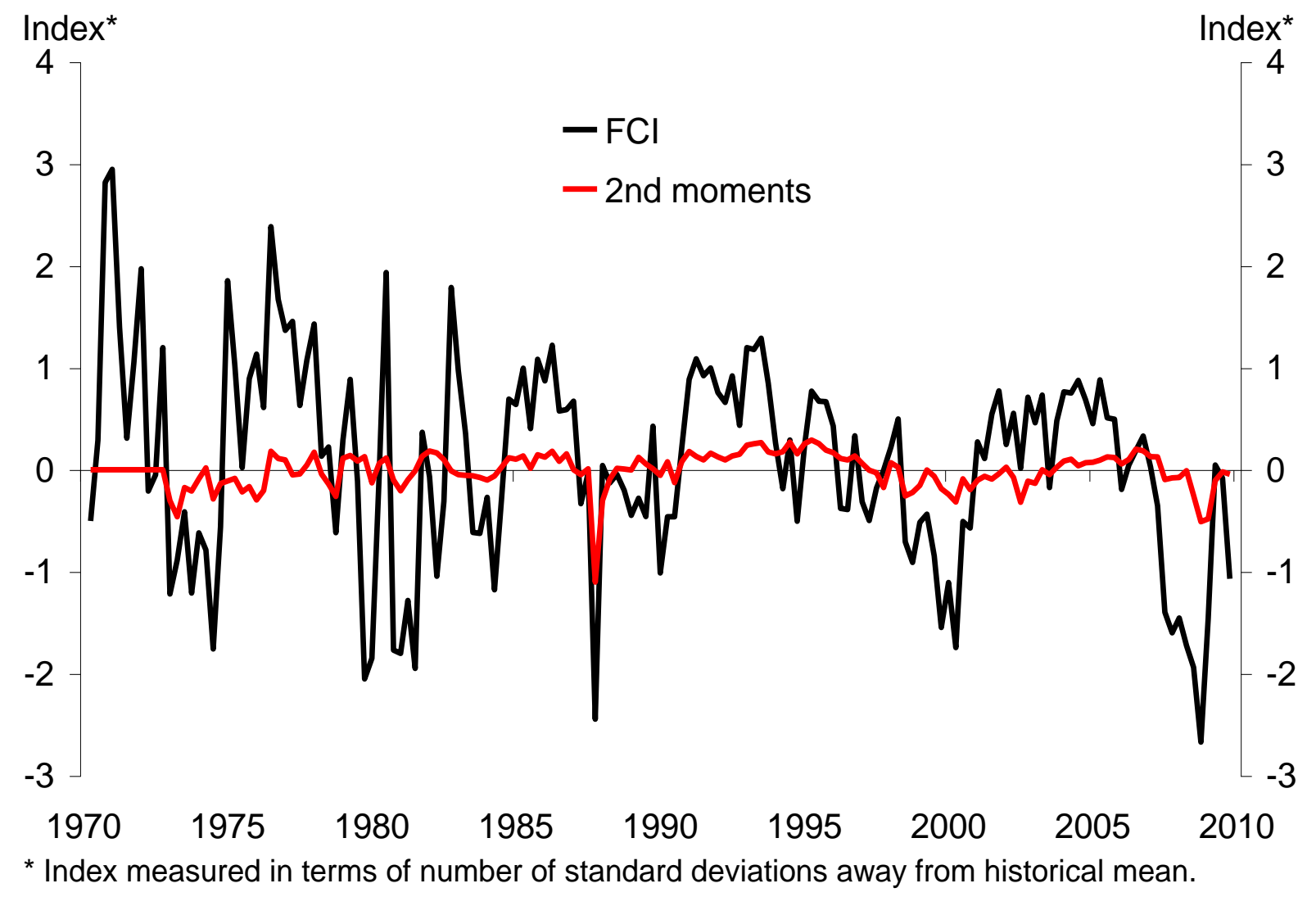


Figure 5.5: FCI with and without purging of business cycle

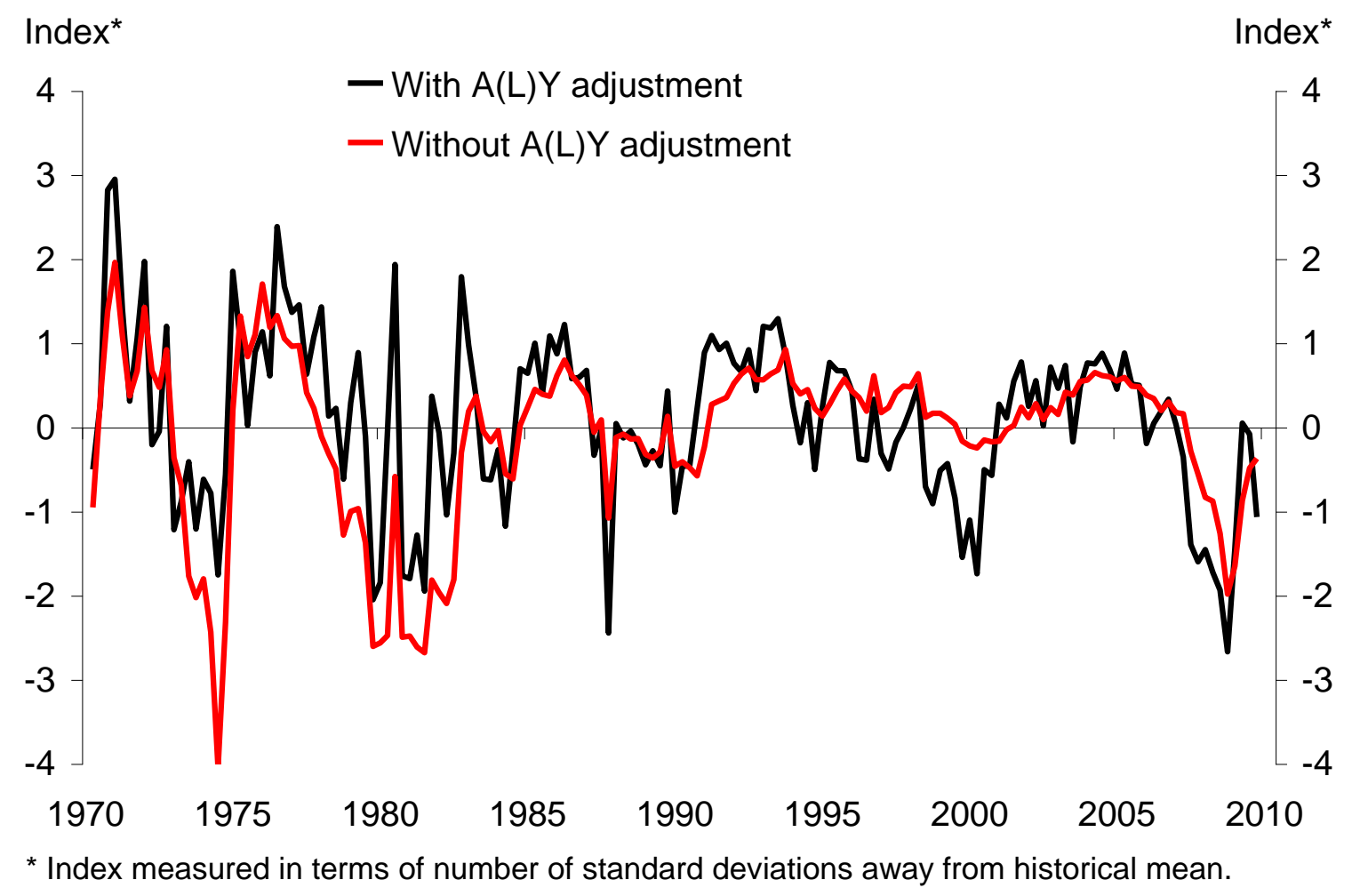


Figure 5.6: FCI and FCI purged of Fed Funds Shocks

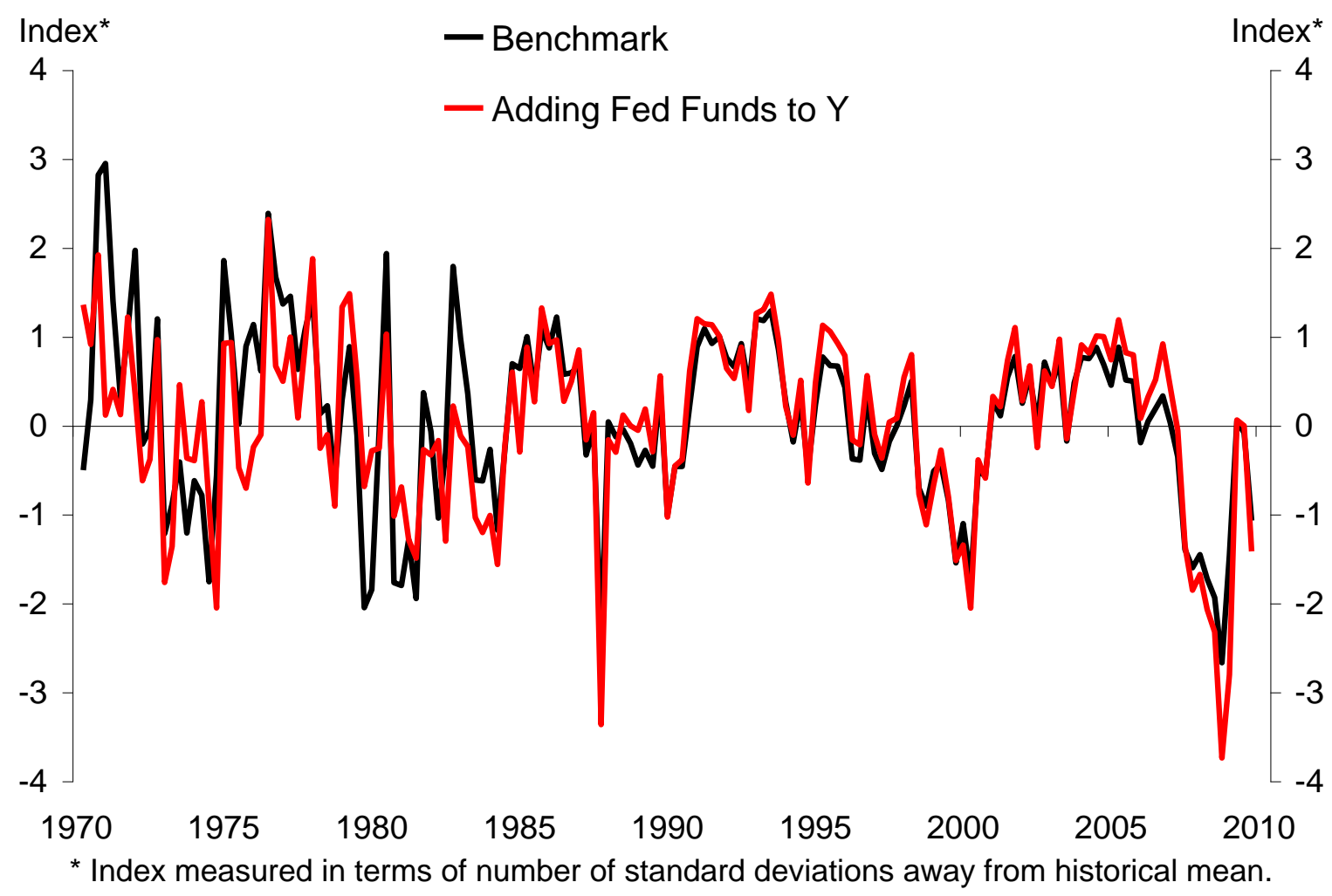


Figure 5.7: Federal Funds and FCI During Periods of Fed Policy Easing and Tightening*

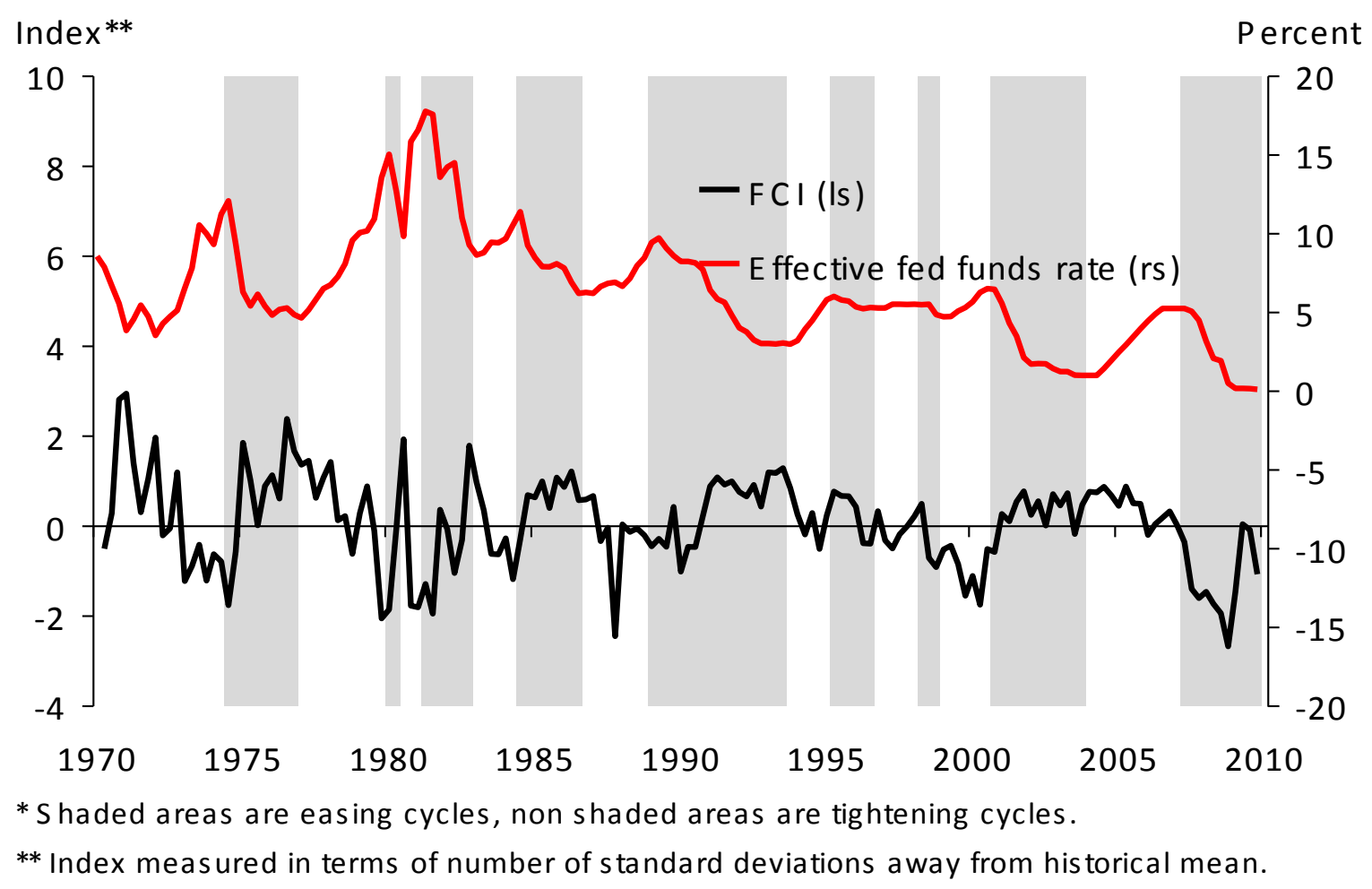




\section{Figure 5.8: New FCI During Periods of Fed Policy Tightening}

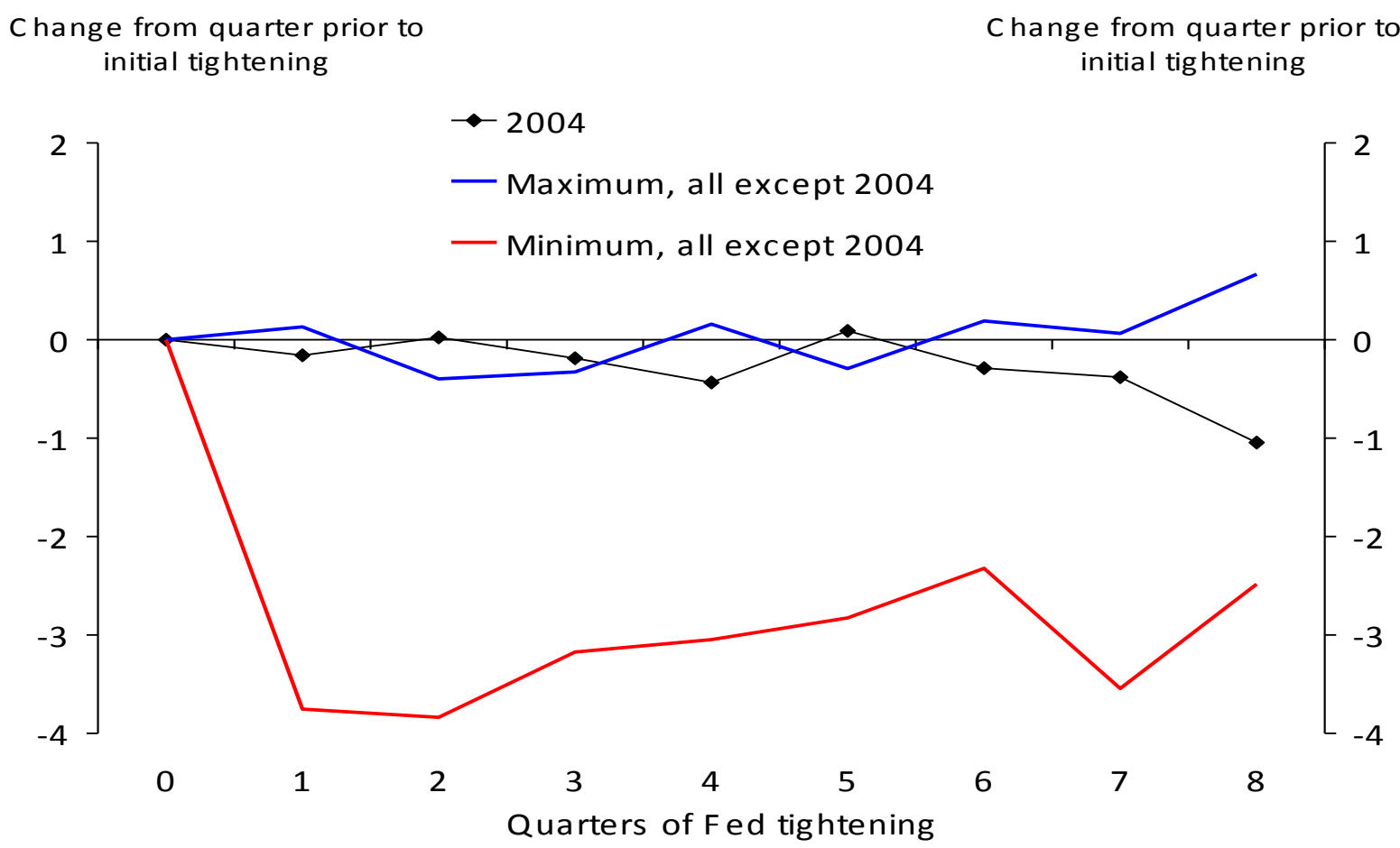

Figure 5.9: New FCI During Periods of Fed Policy Easing

Change from quarter prior to initial easing

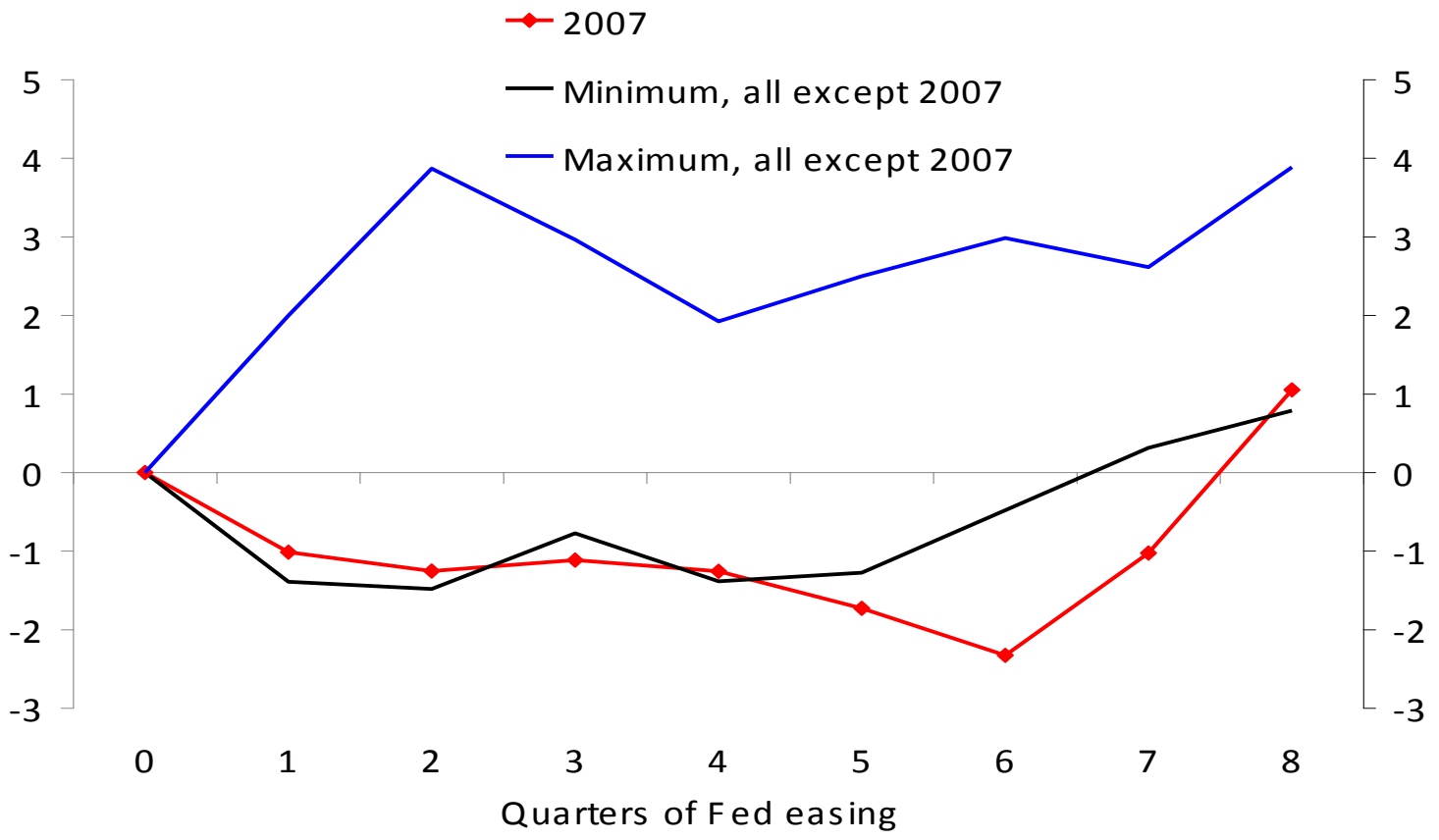


Figure 5.10: Changes in Financial Conditions from 2009Q2 to 2009Q4

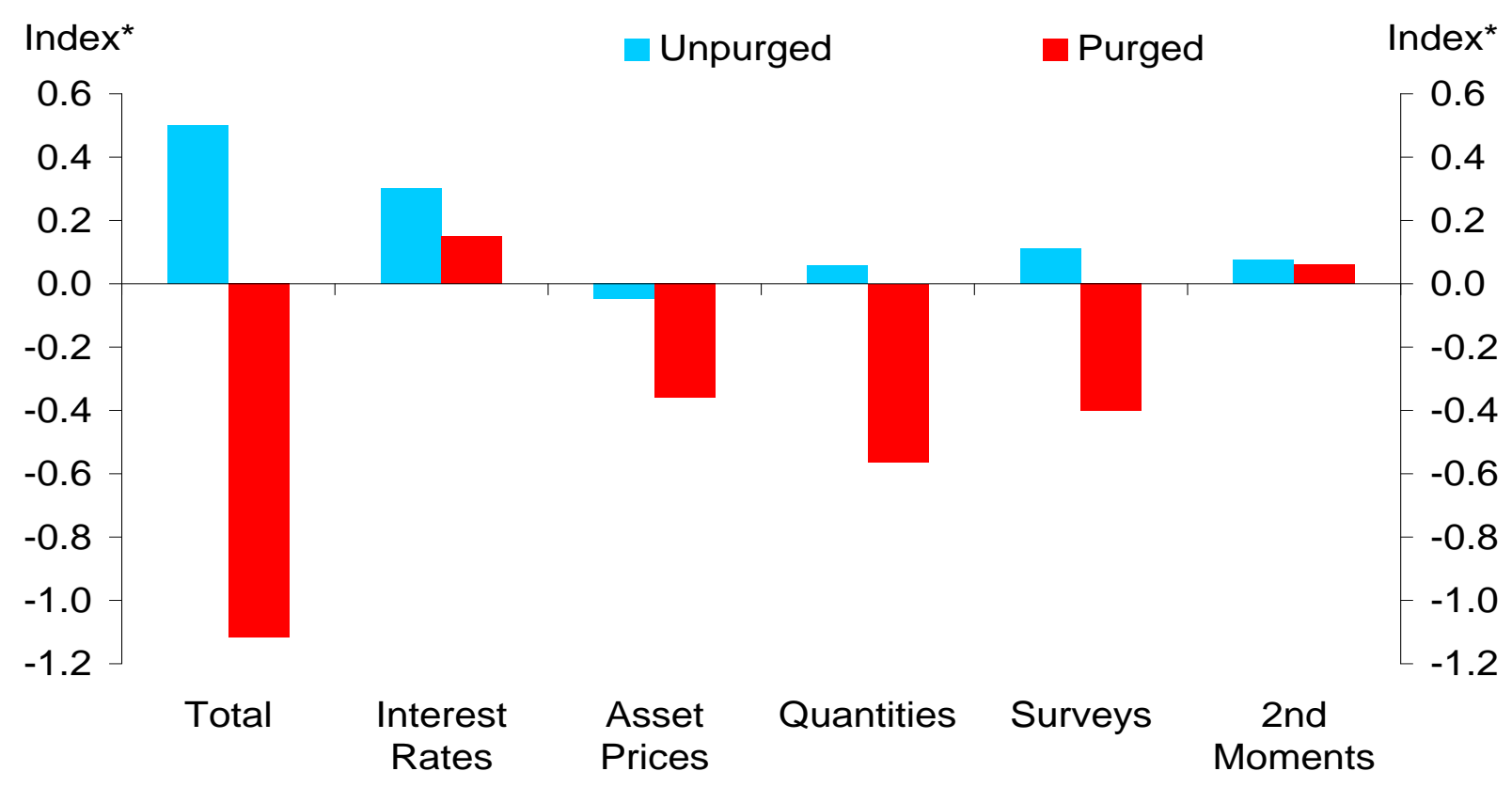

* Index measured in terms of number of standard deviations away from historical mean. 
Table 5.3: Top contributors to decline in new FCI (2009:Q2 to 2009:Q4)

\begin{tabular}{|l|c|c|c|}
\hline Indicator & $\begin{array}{c}\text { FCI } \\
\text { (purged) }\end{array}$ & $\begin{array}{c}\text { FCI (non } \\
\text { purged) }\end{array}$ & Difference \\
\hline $\begin{array}{l}\text { Total Non-mortgage ABS Issuance (Relative to } \\
\text { 8Q MA) }\end{array}$ & -0.20 & -0.01 & -0.19 \\
\hline Financial Market Cap (percent of S\&P 500) & -0.19 & -0.02 & -0.17 \\
\hline ABS Issuers: Assets; Consumer Credit & -0.10 & -0.03 & -0.08 \\
\hline Total Finance: Liabilities - Security RPs & -0.10 & -0.01 & -0.10 \\
\hline Wilshire 5000 & -0.10 & -0.02 & -0.08 \\
\hline ABS Issuers: Asset - Commercial Mortgages & -0.09 & -0.01 & -0.08 \\
\hline $\begin{array}{l}\text { FRB SLO: Banks Tightening C\&I Loans to } \\
\text { Small Firms }\end{array}$ & -0.08 & 0.06 & -0.14 \\
\hline $\begin{array}{l}\text { FRB SLO: Banks Tightening C\&I Loans to } \\
\text { Large Firms }\end{array}$ & -0.08 & 0.05 & -0.12 \\
\hline ABS Issuance (Relative to 24M MA) & -0.07 & 0.02 & -0.09 \\
\hline Loan Performance National House Price Index & -0.07 & 0.00 & -0.07 \\
\hline & & & \\
\hline Sum & $\mathbf{- 1 . 0 8}$ & $\mathbf{0 . 0 2}$ & $\mathbf{- 1 . 1 1}$ \\
\hline
\end{tabular}

Notes: Columns 2 and 3 show the change from 2009:Q2 to 2009:Q4 in the contribution to the FCI from the indicator shown in column 1. 
Figure 5.11: ABS issuance still subdued

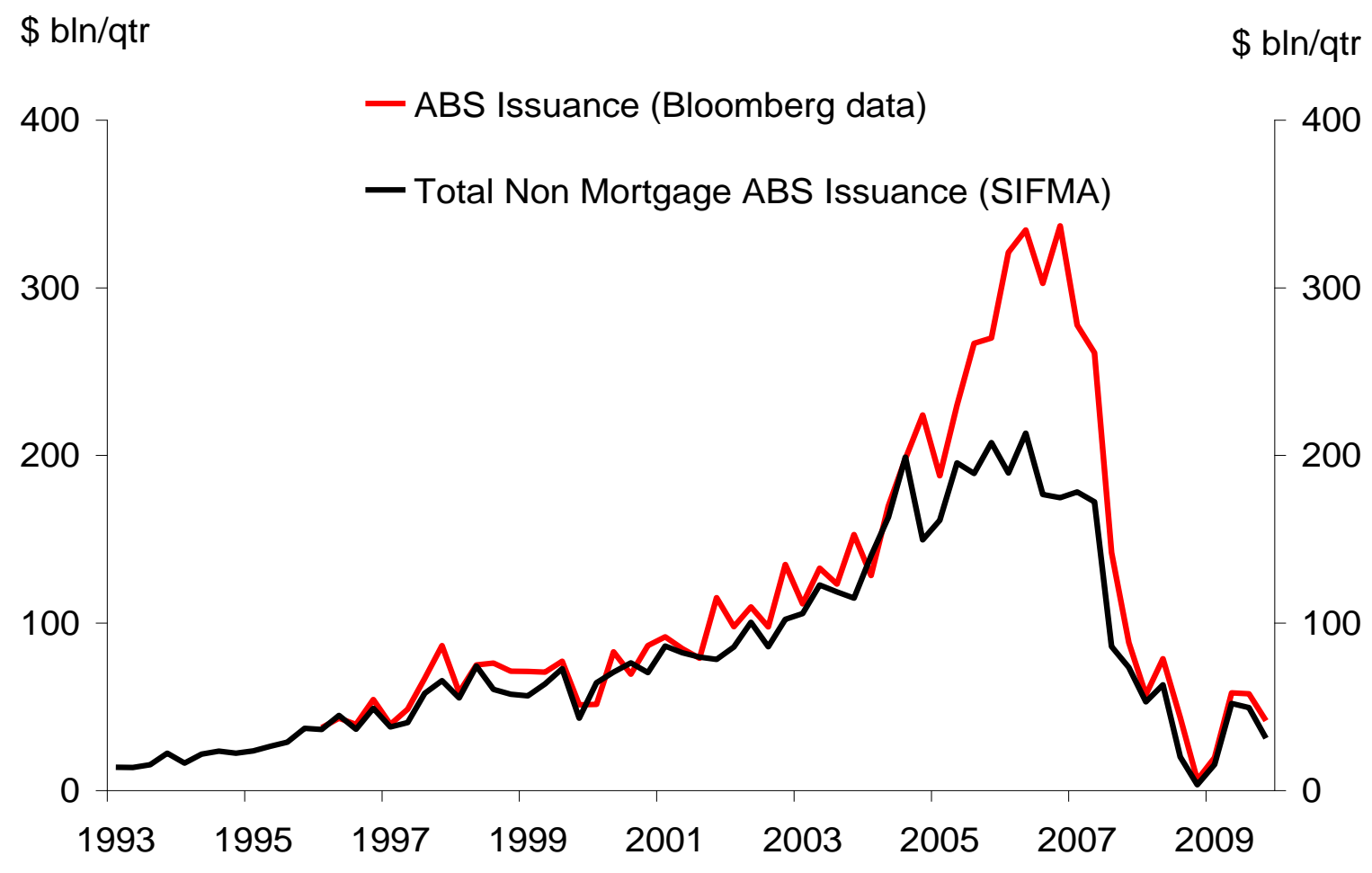

